Elsevier required licence: (C 2018. This manuscript version is made available under the CC-BY-NC-ND 4.0 license http://creativecommons.org/licenses/by-nc-nd/4.0/ 


\title{
High frequency trading and co-movement in financial markets ${ }^{\text {tr }}$
}

\author{
Laura Malceniece, ${ }^{a}$ Kārlis Malcenieks, ${ }^{\mathrm{a}}$ and Tālis J. Putniņš a,b,*

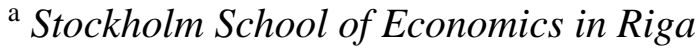 \\ ${ }^{\mathrm{b}}$ University of Technology Sydney
}

Forthcoming, Journal of Financial Economics

\begin{abstract}
Using the staggered entry of Chi-X in 12 European equity markets as a source of exogenous variation in high frequency trading (HFT), we find that HFT causes significant increases in comovement in returns and in liquidity. About one-third of the increase in return co-movement is due to faster diffusion of market-wide information. We attribute the remaining two-thirds to correlated trading strategies of HFTs. The increase in liquidity co-movement is consistent with HFT liquidity providers being better able to monitor other stocks and adjust their liquidity provision accordingly. Our findings suggest a channel by which HFT impacts the cost of capital.
\end{abstract}

Keywords: high frequency trading, HFT, co-movement, commonality, synchronicity, liquidity

JEL classification: G14, G12

\footnotetext{
is We thank the Securities Industry Research Centre of Asia-Pacific (SIRCA) and Thomson Reuters for providing the data used in this study. We are grateful for the comments of the editor (Bill Schwert), an anonymous referee, David Easley, Douglas Foster, Thierry Foucault, Michael Goldstein, Bjorn Hagstromer, Allaudeen Hameed, Petko Kalev, Marta Khomyn, Agnes Lubloy, Ron Masulis, Maureen O'Hara, Terry Walter, Lijian Wei, and conference/seminar participants at the Financial Management Association Asia Pacific Conference, the Q-Group Colloquium, the Australasian Finance and Banking Conference, Nasdaq OMX, Chi-X Australia, the University of South Australia, the University of Technology Sydney, the Stockholm School of Economics in Riga, and the Baltic International Centre for Economic Policy Studies. Putninš gratefully acknowledges funding from the Australian Research Council under grant ARC DE150101889. The Online Appendix that accompanies this paper can be found at goo.gl/4shAeo.

* Corresponding author. Tel.: +61 29514 3088; Fax: +61 295147722.

E-mail address: talis.putnins@uts.edu.au (T.J. Putniņš).
} 


\section{Introduction}

One of the most substantial changes in financial markets during the past decade is the proliferation of algorithmic trading (AT) and high frequency trading (HFT). ${ }^{1}$ While estimates of the scale of HFT activity vary depending on the market and how broadly HFT is defined, there is no doubt HFT accounts for a large share of trading volume in most developed markets. This "rise of the machines" has triggered intense debate between regulators, practitioners, and academics about the effects of HFT. Consensus is forming on some of the positive effects of HFT, with many empirical studies finding that AT and HFT improve simple measures of liquidity such as bid-ask spreads and are beneficial to price discovery. ${ }^{2}$ Less is known about the impact of HFT on stability and systematic risk in markets, including issues that have alarmed regulatory bodies, such as periodic liquidity evaporation, flash crashes, and volatility.

Co-movement in stock returns and in the liquidity of individual stocks is an important aspect of market stability and risk. Co-movement in returns determines the benefits of crosssectional diversification, the level of systematic risk, and therefore can affect companies' cost of capital. Co-movement or "commonality" in liquidity similarly attracts a return premium because investors dislike stocks that become illiquid when the market becomes illiquid (e.g., Acharya and Pedersen, 2005; Anthonisz and Putniņs, 2017). Co-movement also affects the way shocks are transmitted and thus the level of systemic risk. An increase in co-movement could therefore offset some of the benefits of HFT such as increased liquidity.

There are several reasons why HFT is likely to impact co-movement between securities. For example, HFTs tend to withdraw their liquidity when it is most needed by markets - during times of stress and large market-wide price movements. Moreover, HFT strategies involve trading on asset mispricing across and within markets and the strategies of HFTs are similar. Such trading results in correlated demand for groups of stocks, which can increase in the extent to which they co-move. HFT are also better able to monitor conditions in other stocks and adjust their liquidity provision accordingly, thereby synchronizing returns and liquidity across stocks. Despite these reasons, there is scarce evidence on how HFT affects co-movement.

\footnotetext{
${ }^{1}$ AT refers to orders and trades placed and managed by a computer that is programmed with an algorithm. HFT is a subset of AT that is distinguished by considerably higher trading speed, high order-to-trade ratios, and limited inventory positions, typically held for extremely short time periods. Common strategies employed by HFTs include liquidity provision and various forms of arbitrage and quasi-arbitrage.

${ }^{2}$ For example, see Hendershott, Jones, and Menkveld (2011), Riordan and Storkenmaier (2012), Hasbrouck and Saar (2013), Menkveld (2013), Brogaard, Hendershott, and Riordan (2014a), and Brogaard, Hagströmer, Nordèn, and Riordan (2015).
} 
We aim to fill this gap by analyzing the impact of HFT on co-movement in returns and in liquidity. We investigate the time period of 2007-2009 for 12 European equity markets, using the staggered entry of Chi-X as an exogenous instrument for the level of HFT. ${ }^{3}$ The entry of Chi-X provides a good natural experiment because (i) Chi-X led to a substantial increase in HFT due to its low latency and "symbiotic relationship" with HFT (Chordia, Goyal, Lehmann, and Saar, 2013; Menkveld, 2013, 2016), and (ii) Chi-X began trading many different groups of stocks on many different dates, facilitating difference-in-differences estimation with many events. The staggered entry of Chi-X allows us to control for potential confounding effects including time-series trends that are not related to HFT. We also control for fragmentation. We use daily consolidated order books and trades for the 12 European equity markets.

Our main finding is that increased HFT activity leads to greater co-movement in both in returns and liquidity. The increase in co-movement is economically meaningful; a one-standarddeviation increase in HFT increases return co-movement by one-fifth of its mean and liquidity co-movement by two-fifths of its mean. We also find that HFT substantially increases liquidity, narrowing spreads by almost one-half, and increases volatility.

Several mechanisms could contribute to the increase in co-movement. Using models of mediation, we shed light on their relative importance. The quotes of HFTs are faster to incorporate market-wide information (e.g., Brogaard, Hendershott, and Riordan, 2014a), which is one source of increased return co-movement. About one-third of the increase in return comovement is due to faster diffusion of market-wide information. Isolating this channel is important because unlike other causes of return co-movement, faster diffusion of market-wide information makes prices more accurate without necessarily increasing systematic risk. We attribute a small fraction (9\%) of the increase in return co-movement to a "habitat" effect; increased liquidity due to HFT makes stocks more attractive to large investors that trade broad cross-sections of liquid stocks. We attribute the bulk of the increase in return co-movement (56\%) to correlated trading strategies of HFTs such as those documented by Chaboud, Chiquoine, Hjalmarsson, and Vega (2014), and Boehmer, Li, and Saar (2018).

The tendency for HFT liquidity providers to withdraw from the market when conditions are unfavorable (e.g., Anand and Venkataraman, 2016) is a source of fragility that increases both volatility and co-movement in liquidity. We estimate that this mechanism accounts for around

\footnotetext{
${ }^{3}$ Menkveld (2013) and Jovanovic and Menkveld (2016) also use the introduction of Chi-X to study HFT, but they use a single country and focus on different issues concerning HFT.
} 
one-fifth of the increase in liquidity co-movement overall and becomes stronger during the period of high volatility in 2008-2009. Our results suggest the main drivers of the increase in liquidity co-movement are the increased ability of HFT market markers to monitor conditions in other stocks and the correlated liquidity demand of opportunistic HFTs.

The impact of HFT is not uniform in the cross-section of stocks. We find that HFT leads to larger increases in co-movement in returns and in liquidity for medium and low volume stocks. The stronger impact on medium and small stocks is consistent with the notion that prior to HFT, liquidity providers with limited monitoring capacity allocate less effort to monitoring information relevant for small stocks, where the stakes are lower (e.g., Lyle, Naughton, and Weller, 2016). The increase in monitoring capacity brought about by HFT disproportionately increases monitoring of value-relevant information about medium and small stocks, thereby increasing their synchronicity with the rest of the market. Non-uniformity in how HFT affects co-movement is also consistent with a habitat effect; an increase in the liquidity of medium and small stocks due to HFT increases the likelihood that they will be held by large institutions and subsequently co-move with other stocks held by institutions.

Our results have implications for companies and markets. Co-movement in returns and liquidity is a source of systematic risk that is associated with expected return premiums. Therefore, stronger co-movement can increase the cost of capital for companies and impact the real economy through the level of investment by companies. However, because HFT also increases the level of liquidity, which can decrease required returns (e.g., Amihud and Mendelson, 1986), the ultimate effect of HFT on the cost of capital is ambiguous. What is unambiguous is that there are at least three channels by which HFT can affect the cost of capital: the liquidity level, co-movement in returns, and co-movement in liquidity. Stronger comovement also increases the tendency for shocks to propagate across securities, which can affect the level of systemic risk and the propensity for flash crashes.

\section{Related literature and hypotheses}

This section reviews the relevant findings of the literature on AT/HFT (for a more detailed review of HFT see Menkveld (2016)) and on co-movement in returns and in liquidity. Because HFT is a subset of AT, some studies of AT are relevant to understanding the effects of 
HFT. It then draws together insights from both areas to arrive at two hypotheses about the effects of HFT on co-movement.

\subsection{The effects of AT/HFT}

Much of the empirical literature focuses on the effects of AT/HFT on various measures of market quality, such as liquidity and informational efficiency. For example, Hendershott, Jones, and Menkveld (2011) use the staggered introduction of automated quote dissemination on the NYSE in 2003 as an instrument for AT and find that AT has a positive effect on liquidity (reduces quoted and effective spreads). They use the flow of electronic messages normalized by trading volume as a proxy for AT. Our paper is methodologically similar in that it uses a staggered market structure change as an instrument and a normalized electronic message flow proxy, but in contrast, the market structure change that we examine facilitates HFT in particular. Our paper also differs by examining the effects of HFT on co-movement in returns and liquidity, rather than the level of liquidity. Hendershott and Riordan (2013) and Boehmer, Fong, and Wu (2015) find a similar positive effect of AT on liquidity in a sample of Deutsche Boerse stocks and a global sample, respectively.

Hasbrouck and Saar (2013) focus specifically on HFTs. They develop an algorithm to proxy for HFT activity using trade and quote data and find that HFTs decrease spreads and shortterm volatility and increase depth. Similarly, Boehmer et al. (2018) find that increased competition among HFTs, in particular market making HFTs, decreases short-term volatility and increases liquidity. Menkveld (2013) analyzes the entry of Chi-X in the Dutch equity market and in particular the trades of a large market making HFT that subsequently commenced trading Dutch equities. He finds that the HFT market maker displays many of the characteristics of traditional market makers, but has a substantial positive effect on liquidity. Jovanovic and Menkveld (2016) use the same event to calibrate their model of equilibrium HFT and non-HFT trading. They find that the HFT entry decreases adverse selection costs, increases trade frequency, and has a modest positive effect on welfare. Our paper adds to this literature on the effects of HFT by analyzing the impact on co-movement in returns and in liquidity.

The literature also generally finds that HFT has a positive effect on informational

efficiency. For example, Brogaard et al. (2014a) and Carrion (2013) both use a data set of Nasdaq-identified HFTs trading on Nasdaq during 2008-2010 (but apply different methods) and 
conclude that days with a lot of trading by HFTs are associated with higher informational efficiency. HFTs facilitate price discovery by submitting liquidity demanding orders in the direction of permanent price changes and in the opposite direction to transitory pricing errors. HFTs trade in the direction of macroeconomic news announcements, market-wide price movements and limit order book imbalances. Chaboud et al. (2014) study AT in the foreign exchange market using a data set that clearly identifies computer-generated trades. They find that AT improves two measures of informational efficiency: the frequency of arbitrage opportunities and the autocorrelation of high-frequency returns. They show that AT strategies and trades are highly correlated.

Although a number of regulators and practitioners have raised concerns about the effects of HFT on systematic risks, relatively little evidence exists to date. Foucault (2012) concludes his survey of AT/HFT stating that the effect on systematic risk is unclear and more work is needed. This is where our paper contributes to the AT/HFT literature by characterizing the effects of HFT on co-movement in returns and liquidity. The degree of co-movement is an important aspect of market quality as it affects systematic risk, the propagation of shocks, and market stability.

\subsection{Co-movement in financial markets}

The extent to which stock returns co-move determines how effectively diversification, in the form of holding portfolios of stocks, can reduce risk. Similarly, co-movement in liquidity, often referred to as "commonality in liquidity", determines the extent to which variation in liquidity can be reduced by holding portfolios of stocks. Because investors are concerned about liquidity (e.g., Amihud and Mendelson, 1986; Amihud, 2002) systematic variation in liquidity (liquidity "risk") is associated with a return premium. For example, Acharya and Pedersen's (2005) liquidity-adjusted CAPM shows that co-movement in liquidity contributes to liquidity risk and thus attracts an expected return premium. Therefore, co-movement in returns and in liquidity affects asset prices, required returns, and consequently can impact the cost of capital.

A large number of empirical papers study co-movement or commonality in liquidity starting with Chordia, Roll, and Subrahmanyam (2000), Huberman and Halka (2001), and Hasbrouck and Seppi (2001). Brockman, Chung, and Pérignon (2009) find co-movement in 
liquidity in most of the world's stock exchanges. A commonly used measure of co-movement in liquidity is the $\mathrm{R}^{2}$ in a regression of a stock's liquidity on market liquidity.

Both demand-side and supply-side explanations for co-movement in liquidity have been proposed. The demand-side explanations suggest that correlated trading demands and/or correlated sentiment cause co-movement in liquidity, e.g., institutional investors with similar investing styles may exhibit correlated trading patterns (e.g., Koch, Ruenzi, and Starks, 2016). The supply-side explanations suggest shocks to the funding liquidity or inventory risk of liquidity providers cause the co-movement and consistent with this view Hameed, Kang, and Viswanathan (2010) find that co-movement is stronger during market declines. Karolyi, Lee, and Dijk (2012) use a global sample to test various explanations for what causes co-movement in liquidity. Their evidence largely supports demand-side explanations, but does not rule out supply-side effects also playing a role.

Our contribution to this literature on liquidity co-movement is in showing that a major determinant of the amount of co-movement in liquidity is the level of HFT activity. The impact of HFT occurs through both demand-side and supply-side channels, for example, correlated aggressive trading and market making algorithms that are better at monitoring and responding to changing market conditions. Given the level of HFT activity has grown in the past decade, our results are useful for understanding recent time-series trends in the level of liquidity comovement. They also help understand cross-sectional variation in liquidity commonality given that HFT are more active in stocks with particular characteristics.

The determinants of co-movement (or "synchronicity") in returns have also been widely studied. Co-movement in returns is not simply a reflection of co-movement in fundamental values. For example, when a stock is added to an index its degree of return co-movement tends to increase although its fundamentals remain unchanged (e.g., Barberis, Shleifer, and Wurgler, 2005; Claessens and Yafeh, 2012). Such findings suggest that various market frictions, imperfect incorporation of information in prices, or sentiment cause prices to temporarily deviate from fundamentals and influence the degree of return co-movement. Claessens and Yafeh (2012) use a global sample to test various determinants of co-movement in returns. Their evidence largely supports the demand-based explanation that co-movement is driven by correlated shocks to investor demand for a particular set of stocks, but does not rule out the 
"information diffusion" explanation that some stocks reflect market-wide information faster than others.

Our contribution to this literature on return co-movement is in showing that HFT has a significant impact on return co-movement and that this impact is consistent with both demandbased explanations such as correlated trading demands as well as information diffusion effects through faster price discovery.

There are two main interpretations of the $\mathrm{R}^{2}$ from a regression of a stock's returns on market returns (the commonly used measure of return co-movement). The first is that comovement is inversely related to the amount of stock-specific information impounded into prices (e.g., Roll, 1988; Morck, Yeung, and Yu, 2000; Durnev, Morck, Yeung, and Zarowin, 2003; Jin and Myers, 2006; Hutton, Marcus, and Tehranian, 2009). Consistent with this notion, these studies generally find that return co-movement is higher in countries with weaker investor protection and less transparent information environments. The second interpretation is that a low degree of return co-movement can be due to a relatively high amount of stock-specific information and/or a relatively high level of noise in stock prices (e.g., Campbell, Lettau, Malkiel, and Xu, 2001; Chan and Hameed, 2006; Bartram, Brown, and Stulz, 2012).

An increase in the co-movement of returns is likely to be accompanied by an increase in the co-movement of liquidity and vice versa. The first reason is that many of the causes of comovement in either returns or liquidity also cause co-movement in the other variable. For example, correlated shocks to investor demands to trade groups of stocks impact both the returns and the liquidity of those stocks. Similarly, funding constraints of liquidity providers are more likely to impact market-wide liquidity following a market-wide return shock and therefore stronger return co-movement is likely to lead to stronger co-movement in liquidity. Second, liquidity is a priced characteristic and is persistent. A market-wide decrease in liquidity is likely to increase future expected market returns, causing a negative contemporaneous market return. Stronger co-movement in liquidity will therefore lead to stronger co-movement in returns.

\subsection{The effects of HFT on co-movement}

HFT trading strategies can be broadly classified into (i) market making strategies and (ii) opportunistic strategies (comprising arbitrage, momentum, and other strategies). Hagströmer and Nordén (2013) analyze these two types of strategies in the Nasdaq OMX Stockholm market. 
They find that HFT market makers account for the majority of HFT volume and HFT orders and, as expected, supply liquidity more often than opportunistic HFTs.

Importantly, there are reasons why both market making and opportunistic HFTs are likely to increase co-movement in returns and in liquidity. First, opportunistic HFTs are likely to demand liquidity in a number of stocks at the same time. For example, statistical arbitrage often involves simultaneously taking long and short positions in a number of stocks that appear relatively mispriced. The different legs of the strategy must be transacted around the same time to avoid price movements while the strategy is only partially implemented. Similarly, momentum strategies can involve placing long and short positions on different stocks at the same time. Furthermore, opportunistic HFTs use similar strategies to one another, based on similar signals, which can further amplify the correlation in liquidity demand across stocks (e.g., Chaboud et al., 2014; Biais and Woolley, 2011; Boehmer et al., 2018). Jarrow and Protter (2012) highlight that opportunistic HFTs can have a destabilizing effect when they unknowingly coordinate on a common signal. In extreme cases, such as the "quant meltdown" of 2007 (see Khandani and Lo, 2011), opportunistic HFTs may all earn large profits or make large losses at the same time and thus increase their activity or withdraw from the market at the same time. Time-series variation in opportunistic HFT activity can therefore increase co-movement in liquidity and in returns.

Second, market making HFTs are also likely to increase co-movement in liquidity and in returns through (i) increased monitoring of related securities, and (ii) correlated liquidity withdrawals when conditions become unfavorable. Cespa and Foucault (2014) model market makers that condition their liquidity provision on the prices of other stocks and show that such "price watching" gives rise to cross-asset liquidity spillovers. In their model, market makers in a stock $\mathrm{X}$ infer a noisy signal about the stock's fundamental value by observing the prices of another stock, Y. An exogenous liquidity shock to stock Y causes the prices of stock Y to give a noisier signal about the value of stock $X$. The increased uncertainty about the fundamental value of stock $\mathrm{X}$ causes the market makers to scale back their liquidity provision in stocks $\mathrm{X}$, leading to a liquidity spillover.

In addition to liquidity spillovers, which increase co-movement in liquidity, pricewatching market makers cause price changes in one stock to be rapidly reflected in the prices of other stocks, thereby increasing return co-movement. Cespa and Foucault's (2014) model 
predicts that liquidity spillovers (and thus also co-movement) will be stronger in the presence of a larger number of price-watching market makers. HFT market makers, compared to traditional market makers, are better able to automatically monitor the prices and market conditions of many other stocks and use this information in optimally setting quotes (Hendershott and Riordan, 2013); in the language of Cespa and Foucault (2014) HFTs are more likely to be price watchers. Therefore, an increase in HFT market making is likely to increase liquidity spillovers and comovement in liquidity and in returns. Lyle et al. (2016) show that the enhanced monitoring ability of AT/HFT is the main reason they tend to increase liquidity. Similarly, Boehmer et al. (2018) argue that one of the reasons that HFT tend to face lower adverse selection risks and thus increase liquidity (decrease short-term volatility) is that they are better able to extract signals from related same-industry securities and from the market index.

Although evidence suggests AT/HFT market makers tend to increase liquidity on average (e.g., Hendershott et al., 2011, Hasbrouck and Saar, 2013), their lack of affirmative obligations allows them to withdraw from the market and suspend liquidity provision during unfavorable market conditions (e.g., Anand and Venkataraman, 2016). A concern raised by regulators and practitioners is that HFTs suspend liquidity provision during times when liquidity provision is most needed - when information asymmetry or perceived asymmetry is high, or the market is in a period of stress. This endogenous liquidity provision can amplify variation in liquidity, and to the extent that HFTs suspend liquidity provision in a number of stocks at the same time, it is likely to further increase co-movement in liquidity and in returns. An extreme example is the "flash crash" of May 2010. Kirilenko, Kyle, Samadi, and Tuzun (2017) find that HFTs did not trigger the flash crash but exacerbated the initial liquidity shock by withdrawing from the market or switching from providing liquidity to demanding liquidity. Similarly, the dynamic trading model of Ait-Sahalia and Saglam (2013) predicts that volatility leads HFTs to reduce their provision of liquidity. Because volatility has a systematic or market-wide component, the variation in HFT liquidity provision will also have a market-wide component.

Based on the discussion above, our two hypotheses are as follows.

Hypothesis 1: HFT increases co-movement in returns

Hypothesis 2: HFT increases co-movement in liquidity 
In general, co-movement in returns and in liquidity is a concern for investors because it limits the usefulness of diversification and thus contributes to systematic return and liquidity risks. There is, however, another reason why HFT is likely to increase co-movement in returns and in liquidity that does not necessarily increase systematic risk. Biais, Foucault, and Moinas (2015) and Foucault, Hombert, and Roşu (2016) argue that HFTs' ability to react more quickly to public information will increase the informativeness of prices, in particular the speed at which they reflect public information. Consistent with this prediction, Carrion (2013), Brogaard et al. (2014a), and others find that HFTs increase informational efficiency and cause prices to reflect information faster. Faster incorporation of market-wide information across stocks can increase stock price synchronicity and return co-movement. For example, Chordia, Sarkar, and Subrahmanyam (2011) find that the returns of small stocks tend to follow those of large stocks. They attribute this finding to market-wide information being first reflected in the prices of large stocks, which are followed by a large number of analysts and traded by institutional investors, and then gradually transmitted from large to small stocks. Because the cross-correlations occur with a lag, contemporaneous correlations fail to measure the full extent of return co-movement. ${ }^{4}$ When the informational efficiency of prices increases, particularly when less informationally efficient stocks become faster in reflecting market-wide information, contemporaneous comovement should increase. This mechanism by which HFT can increase co-movement can be distinguished from the other mechanisms by isolating the increase in co-movement that is due to decreased delay in impounding market-wide information.

\section{Data}

Our sample period is from February 1, 2007, to February 27, 2009, which covers two months prior the first Chi-X entry in Europe (starting with the Dutch and German markets) and extends to two months after Chi-X started to operate in Spain. During this period, Chi-X commenced trading equities from 13 European countries: Austria, Belgium, Denmark, France, Finland, Germany, Italy, the Netherlands, Norway, Spain, Sweden, Switzerland, and the United Kingdom (UK). We include all of these countries in our sample, except Switzerland due to data deficiencies. We exclude the effects of the financial crisis (which falls during our sample period)

\footnotetext{
4 The failure of contemporaneous correlations to adequately measure the extent of co-movement is why nonsynchronous trading causes a downward bias in market betas (e.g., Scholes and Williams, 1977; Dimson, 1979).
} 
from our analysis by using a difference-in-differences approach that sweeps out time-series variation in co-movement that occurs for reasons other than changes in HFT activity.

We construct a sample of stocks from each of the European countries as follows. First, we include all stocks that at any time within our sample period are traded on the Chi-X platform. Second, we include the top 75 stocks from each country based on aggregate trading volume during the sample period. ${ }^{5}$ Many (but not all) of the top 75 stocks in each country are at some stage traded on Chi-X, in which case we do not duplicate them in the sample. Our results are robust to using the top $20 \%$ of stocks per country rather than the top 75 stocks (Online Appendix Section 2). The main difference between these two sampling approaches is that using the top 75 stocks results in approximately equal weights on each of the 12 countries in the sample, whereas using the top $20 \%$ of stocks places greater weight on markets that have more listed stocks because they end up having more stocks in the aggregate sample. Following Hendershott et al. (2011), stocks with a price above EUR 1,000 are omitted. Our final sample comprises 1,311 stocks and 674,307 stock-day observations.

Fig. 1 shows the sequence in which Chi-X commenced trading European stocks and the total number of stocks traded on the platform, grouped into terciles by volume. There are zero stocks traded on Chi-X at start of the sample and the first step change occurs with the entry of Chi-X in Germany and the Netherlands. The addition of other countries' stocks follows a step function with the changes distributed fairly evenly through time, which is favorable for our quasi-experimental econometric design. By the end of our sample, Chi-X is trading close to 400 of the top tercile stocks (T3), and close to 200 stocks from each of the middle and lowest terciles (T2 and T1). Consequently, our sample of stocks also contains a considerable number of stocks that are not traded on Chi-X even by the end of the sample period. Such stocks contribute to the analysis as controls for any confounding time-series trends.

\section{$<$ Fig. 1 here >}

We obtain intraday data on trades and quotes, aggregated at an hourly frequency, from the Thomson Reuters Tick History data set, maintained by SIRCA. The data include the best bid and ask quotes at the end of the hourly interval, as well as the number of trades, the traded

\footnotetext{
${ }^{5}$ The reason for including this second group of stocks is so that the sample also contains some stocks that do not end up traded on Chi-X. Such stocks act a further control group in our difference-in-differences model.
} 
volume, the volume-weighted average price and the number of electronic messages during the hourly interval. ${ }^{6}$ For each stock, we obtain trade and quote data for (i) the home market (its primary listing), (ii) Chi-X (if the stock is traded on Chi-X), and (iii) all other exchanges and multilateral trading facilities that trade the stock (see the Appendix for the list of exchanges/MTFs for which we consolidate data). For each stock we merge the data from all of the venues in which it is traded to construct consolidated order books and consolidated records of trading activity. After calculating liquidity proxies (described below) we aggregate the hourly data to stock-day observations for the instrumental variables panel regressions. For metrics that require comparisons of value (e.g., dollar volume) across countries, we convert values into EUR.

We exclude weekends and national holidays in each country. In constructing daily aggregates, we use trading activity between 8:00am and 4:30pm Greenwich Mean Time (GMT). ${ }^{7}$ Quotes or trades that are more than $20 \%$ away from the price on the home exchange are excluded. We winsorize all variables at the 0.5 and 99.5 percentiles within each country.

\section{Measures and descriptive statistics}

Table 1 provides definitions of the measures of HFT activity, liquidity, fragmentation, and control variables, along with descriptive statistics. Below we elaborate on how we compute the most important of these measures.

\section{$<$ Table 1 here >}

\subsection{HFT measures}

We use proxies for HFT activity based on electronic message traffic, similar to Hendershott et al. (2011) and Boehmer et al. (2015). ${ }^{8}$ The first proxy, HFTvolume H,t $_{\text {, }}$ is negative trading volume (in EUR 100) divided by the number of quote messages:

\footnotetext{
6 The number of electronic messages is defined as the sum of best bid and best ask updates during the interval, where an update is a change to the price or quantity at either the best bid or offer. This captures all order submissions, amendments and cancellations, at or within the best prevailing quotes.

${ }^{7}$ To avoid consolidating across exchanges with very different trading hours we exclude exchanges in time zones that that are more than three hours ahead of or behind GMT.

${ }^{8}$ Hendershott et al. (2011) and Boehmer et al. (2015) use these measures as proxies for algorithmic trading (AT), which includes HFT but is somewhat broader. Given HFT is a subset of AT, an increase in HFT activity will be reflected in higher values on these measures of AT. Our main analysis focuses on the changes in these measures as a result of the introduction of Chi-X. Because Chi-X specifically distinguished itself on the basis that it was a low latency trading platform, it primarily stimulated HFT activity (Chordia et al., 2013; Menkveld, 2013, 2016; Jovanovic and Menkveld, 2016) rather than AT more broadly. Therefore, the majority (if not all) of the variation in
} 


$$
\text { HFTvolume }_{i, t}=-\frac{\text { dvol }_{i, t}}{100 \text { messages }_{i, t}},
$$

where $i$ is a stock, $t$ is a trading day, $d v o l_{i, t}$ is consolidated trading volume, messages $s_{i, t}$ is the number of electronic messages. The second proxy for HFT is the number of messages divided by the number of trades in each day:

$$
\text { HFTtrades }_{i, t}=\frac{\text { messages }_{i, t}}{\text { trades }_{i, t}},
$$

where $\operatorname{trades}_{i, t}$ is the number of trades for stock $i$ on day $t$. The intuition behind both of these measures is that the main indicator of HFT activity is increased message traffic, because computers are able to place orders at a very high speed and algorithms constantly search and exploit small trading opportunities; therefore, they submit large amounts of messages each day. Messages include order submissions, modifications, and cancelations. Both HFT proxies normalize message traffic by volume or trade counts. We calculate both HFT proxies separately for the stock's home exchange, Chi-X, and the consolidated market. We find similar results across these three versions and therefore use the consolidated version in this paper.

Figs. 2 and 3 plot the time-series of message traffic and HFT activity (HFTvolume $i, t$ ), respectively, for terciles of our sample stocks. In all terciles, message traffic increases through time. The increase is not due to changes in overall volume because message traffic normalized by volume $\left(\right.$ HFTvolume $\left._{i, t}\right)$ also increases through time. Part of the increase in message traffic and HFT activity (if not most) is attributable to the entry of Chi-X in a staggered fashion throughout our sample period (we confirm this in regressions below). Stocks in the highest volume tercile (T3) experience the largest growth in message traffic and in HFT activity. This result is consistent with the fact that proportionally more of the T3 stocks end up traded on ChiX (Fig. 1).

\section{$<$ Fig. 2 here $>$ \\ $<$ Fig. 3 here >}

Table 1 shows that there is a higher proportion of HFT activity on Chi-X compared to the home exchange. For example, the ratio of electronic messages to trades $\left(\right.$ HFTtrades $\left._{i, t}\right)$ has an

the AT measures around the entry of Chi-X is likely to be driven by variation in HFT and thus in our analysis we refer to these measures as proxies for HFT. 
average of 17.26 in the home market and a staggering 192.34 in Chi-X. The descriptive statistics on the HFT measures have many similarities with what Hendershott et al. (2011) report for the US markets. For example, there is more message traffic in higher volume (larger) stocks (attributable to their higher overall trading activity), the HFT proxies have lower averages for larger stocks (primarily due to the pre-Chi-X periods) and converge to a similar level for all stock size categories after the entry of Chi-X.

\subsection{Liquidity measures}

Following Karolyi et al. (2012), who analyze the causes of co-movement in liquidity, in our baseline analysis we use Amihud's (2002) measure of illiquidity, inverted so that it becomes a measure of liquidity, $L I Q_{i, t}$. Amihud's measure is based on the price impact of trading volume and is strongly positively related to other liquidity estimates like the bid-ask spread, depth, and price impact measured using tick-by-tick data (Amihud, 2002; Goyenko, Holden, and Trzcinka, 2009; Hasbrouck, 2009). ${ }^{9}$

We calculate our main liquidity measure each stock-day as follows:

$$
L I Q_{i, t}=-\log \left(1+\sum_{h=1}^{H}\left(\frac{1}{H} \frac{\left|r_{i, t, h}\right|}{d v o l_{i, t, h}}\right)\right)
$$

where $\left|r_{i, t, h}\right|$ is the absolute midquote return in basis points (bps) for stock $i$ in hour $h$ of day $t$, and $d$ vol $_{i, t, h}$ is hourly consolidated volume (in EUR '000). The log makes the distribution of $L I Q_{i, t}$ closer to a Normal distribution and the multiplication by -1 reverses the interpretation from illiquidity to liquidity.

In robustness tests we find similar results using the relative quoted bid-ask spread in bps as an alternative measure of liquidity:

$$
\operatorname{SPREAD}_{i, t}=\sum_{h=1}^{H}\left(\frac{1}{H} 10,000 \frac{A s k_{i, t, h}-\operatorname{Bid}_{i, t, h}}{\left(A s k_{i, t, h}+B i d_{i, t, h}\right) / 2}\right),
$$

where $A s k_{i, t, h}$ and $B i d_{i, t, h}$ are the ask and bid quotes at the end of hour $h$ for stock $i$ on day $t$.

Table 1 shows that both liquidity measures monotonically increase across the volume terciles (higher volume stocks are more liquid). Chi-X has a narrower average spread than the home market, despite the fact that volume on Chi-X is less than that of the home market. The

\footnotetext{
${ }^{9}$ Goyenko et al. (2009) compare high-frequency liquidity measures with monthly and annual measures and find that in the post-decimalization period (after 2001) the correlation between effective spread and Amihud's measure increases, in contrast to other liquidity measures. Amihud's measure is also used in the literature on how liquidity risk affects asset prices (e.g., Acharya and Pedersen, 2005).
} 
narrower spreads on Chi-X are consistent with Menkveld's (2013) finding that Chi-X encourages highly competitive HFT market makers to provide liquidity.

\subsection{Market fragmentation measures}

An increase in the number of venues in which a stock is traded makes liquidity more dispersed and can affect the overall level of liquidity (Bennett and Wei, 2006). To control for such effects we estimate four market fragmentation proxies. $F R A G 1_{i, t}$ is the number of trading venues that have executed trades in stock $i$ on day $t$. The larger the number of venues, the more fragmented is trading. Table 1 shows that across the full sample, stocks on average trade in 3.57 venues, with a tendency for higher volume (larger) stocks to trade in more venues than lower volume stocks.

Our second fragmentation measure, $F R A G 2_{i, t}$, is the Herfindahl-Hirschman Index (HHI), which is used by Degryse, de Jong, and van Kervel (2015) in analyzing fragmentation in European equity markets:

$$
F R A G 2_{i, t}=1-\sum_{j}\left(\frac{d v o l_{i, j, t}}{\sum_{j} d v o l_{i, j, t}}\right)^{2},
$$

where $d v o l_{i, j, t}$ is volume of stock $i$ on market $j$ on day $t$. FRAG $3_{i, t}$ is similar to the second measure, except it is calculated using the number of trades instead of trading volume. The last fragmentation proxy, $F R A G 4_{i, t}$, is the volume market share of all venues other than home exchange (range: zero to one). We use $F R A G 2_{i, t}$ in our baseline tests. Our results are robust to using the other measures.

\subsection{Co-movement measures}

A long line of literature analyzes co-movement or "commonality" in returns and liquidity. Following Morck et al. (2000), Hameed et al. (2010), and Karolyi et al. (2012), we measure co-movement in returns (liquidity) using the $\mathrm{R}^{2}$ from regressions of individual stock returns (liquidity) on market returns (market liquidity). High $\mathrm{R}^{2}$ indicates a high degree of comovement-much of the variation in the individual stock returns or liquidity is explained by market-wide variation. For each stock in each month we estimate the following regressions using daily observations:

$$
r_{i, t}=\alpha_{i}^{r}+\sum_{j=-1}^{1} \beta_{i, j}^{r} r_{m, t+j}+\varepsilon_{i, t}^{r}
$$


where $r_{i, t}$ is the daily midquote return for stock $i, r_{m, t+j}$ is the market return in the country of stock $i$ calculated as the equally weighted average of returns for all stocks in the country (excluding stock $i$ ). ${ }^{10}$ The lead and lag terms in the regression account for non-synchronous trading in the spirit of Dimson (1979). Logit transformation of the regression $\mathrm{R}^{2}$ to make it into an unbounded variable (as per Morck et al., 2000; Hameed et al., 2010; Karolyi et al., 2012) gives our measure of co-movement in returns (for stock $i$ in month $\tau$ ):

$$
R_{i, \tau}^{2, r}=\ln \left(\frac{R^{2}}{1-R^{2}}\right)
$$

We estimate co-movement in liquidity in a similar way, but include an additional step (a regression estimated for each stock using the full sample) that removes persistence in liquidity and day-of-the-week seasonality (similar to Karolyi et al. (2012)):

$$
L I Q_{i, t}=\beta_{i} L I Q_{i, t-1}+\sum_{j=1}^{5} \gamma_{i, j} D_{j}+\omega_{i, t}^{L I Q},
$$

where $D_{j}$ is a set of dummy variables for each of the working days of the week. The residuals, $\omega_{i, t}^{L I Q}$, are purged of first order serial correlation and day-of-the-week effects and are therefore used to estimate co-movement in liquidity in a similar manner to the procedure for returns:

$$
\begin{gathered}
\widehat{\omega}_{i, t}^{L I Q}=\alpha_{i}^{L I Q}+\sum_{j=-1}^{1} \beta_{i, j} \widehat{\omega}_{m, t+j}^{L I Q}+\varepsilon_{i, t}^{L I Q}, \\
R_{i, \tau}^{2, L I Q}=\ln \left(\frac{R^{2}}{1-R^{2}}\right) .
\end{gathered}
$$

Similar to the procedure for returns, $\widehat{\omega}_{m, t+j}^{L I Q}$ is the equal-weighted average of all individual stocks' liquidity residuals (excluding stock $i$ ) in each country. Our results are robust to using volume-weighting and using the bid-ask spread as an alternative measure of liquidity. For a valid estimate of co-movement in returns or liquidity, we require a minimum of 15 valid daily observations in regressions (6) and (9).

Table 2 reports descriptive statistics on co-movement in returns, liquidity, and in HFT volume, for stock terciles as well as separately for each country in the sample. To simplify interpretation of the magnitudes, Table 2 reports the co-movement measures before the logit transformation, i.e., the regression $\mathrm{R}^{2} \mathrm{~s}$. Higher volume stocks (T3) tend to have stronger comovement with their respective markets in terms of returns, liquidity, and HFT volume. The countries with the highest average co-movement in returns are Sweden $\left(\mathrm{R}^{2}\right.$ of $\left.51 \%\right)$, France,

\footnotetext{
${ }^{10}$ We exclude stock $i$ to avoid spurious relationship in case the stock is a large proportion in the index and correlation between dependent and explanatory variables.
} 
Germany, and the UK, whereas the lowest co-movement occurs in Belgium $\left(\mathrm{R}^{2}\right.$ of $\left.24 \%\right)$, Austria, Finland, and Denmark. Co-movement in liquidity follows a similar pattern across countries, i.e., co-movement in returns is positively correlated with co-movement in liquidity. Interestingly, co-movement in HFT volume across stocks also shows similar patterns to comovement in liquidity for different countries and across stock terciles. Thus, it appears there is commonality in the co-movement measures, suggesting common causes drive co-movement in returns, liquidity, and HFT volumes.

$<$ Table 2 here $>$

\section{Analysis of HFT's impact on co-movement}

We exploit the staggered entry of Chi-X in the European markets as an instrument for the level of HFT activity. Chi-X distinguished itself from the traditional national stock exchanges by having a considerably faster trading platform. ${ }^{11}$ It was therefore conducive to HFT and rapidly captured market share from the national stock exchanges. Having an instrument that affects different markets at different points in time has the advantage of allowing us to control for confounding factors using time fixed effects. The international sample, spanning several markets, reduces the chance that our findings are specific to a particular market.

For the Chi-X entry to be a valid instrument it has to be exogenous, relevant, and not affect co-movement directly, only through its impact on HFT. First, we confirm its relevance using F-tests in the first-stage regressions, strongly rejecting the null hypothesis that the instrument is not a determinant of HFT activity. Second, there is little doubt that the entry of Chi-X is exogenous with respect to co-movement. Chi-X was a response to the European Union's Markets in Financial Instruments Directive (MiFID), which enabled competition between trading venues. ${ }^{12}$ Third, while there are several reasons why the entry of Chi-X would impact co-movement through its effects on HFT, it is unlikely that the Chi-X entry has a direct

\footnotetext{
${ }^{11}$ For example, a Chi-X press release on April 7, 2008, claims that Chi-X is "up to 10 times faster than the fastest European primary exchange".

${ }^{12}$ Chi-X commenced trading stocks from different countries sequentially and within each country starting with the largest stocks and progressively adding smaller stocks. In many countries, Chi-X added the constituents of the market's large capitalization index first and only after confirming that there are no technical problems with trading those stocks did it expand its coverage to constituents of a broader market index. The sequence in which stocks are added to Chi- $\mathrm{X}$ is therefore exogenous (this does not mean that it is unrelated to observable characteristics such as size).
} 
effect on co-movement independent of its effect on HFT. Chi-X impacts other market characteristics such as volume and fragmentation for reasons that could be associated with, or independent of, HFT. We therefore control for market characteristics in the instrumental variables regressions, including volume, volatility, fragmentation, and price level. This ensures we are not picking up, for example, the effects of fragmentation on co-movement.

Other studies of AT/HFT also use a variety of market structure changes to help establish causality. Most of these studies use changes within a single market or a single event, for example, the introduction of automated quote dissemination at the NYSE (Hendershott et al., 2011), the entry of Chi-X in Dutch equities (Menkveld, 2013; Jovanovic and Menkveld, 2016), the introduction of co-location at Nasdaq OMX Stockholm (Brogaard, Hagströmer, Nordèn, and Riordan, 2015), technology upgrades at the London Stock Exchange (Brogaard et al., 2014b), and short selling bans (Brogaard, Hendershott, and Riordan, 2017). Boehmer et al. (2015) use an international sample, exploiting the introduction of co-location in a number of markets.

Does the choice of market or exogenous shock matter in analyzing HFT? Several factors suggest HFT have a fairly consistent impact across different developed markets, making it likely that results from one market or markets generalize to others, and making the choice of sample in most cases a non-critical factor. First, the existing literature examines a variety of developed markets and different exogenous shocks and, across these varied settings, finds fairly cohesive results about how HFT affects markets (e.g., HFT tend to increase liquidity and lead to faster price discovery). To the extent that we also measure some market characteristics that have been previously studied, our results are consistent with findings from other markets. For example, consistent with the literature, we find that a shock that reduces latency in trading (the introduction of Chi-X) substantially increases the level of HFT activity and that the increase in HFT is associated with an increase in liquidity. Second, in an international comparison of the effects of AT/HFT on European, US, and Asian markets, Boehmer et al. (2015) find that AT/HFT have remarkably consistent effects across markets. One of the factors that contributes to the consistency across markets is that the major HFT firms are global and implement similar or identical trading strategies/algorithms in a number of different markets. This is also true in our sample - the major HFTs that commence trading following the entry of Chi-X include the major global firms that also trade the US and Asian markets (e.g., Menkveld, 2013). Third, equity markets in developed countries are relatively similar with respect to the major market 
design features (e.g., they tend to be electronic, centralized, automated limit order book markets, with anonymity, similar trading platforms, fragmentation of trading, and so on). There are of course also differences across markets, but the differences tend to be secondary design features or matters of degree (e.g., extent of fragmentation). Consequently, when global HFT firms trade across similar market structures in different countries, it is reasonable to expect similar effects.

Although the major effects of HFT in most markets are likely to be similar, some variation across markets will prevail. We ensure that our results are not overly driven by a particular market by drawing on a broad sample of countries. Any effects that are specific to a particular country have a relatively small influence on our overall results, which reflect the average or common effects in multiple markets.

We start by estimating the effects of Chi-X on HFT activity and other market characteristics using an ordinary least squares (OLS) panel regression on stock-day observations:

$$
Y_{i, t}=\alpha_{i}+\gamma_{t}+\beta D_{i, t}^{\text {Chi-X }}+\varepsilon_{i, t},
$$

where $Y_{i, t}$ is one of the two HFT proxies, message traffic, volume, inverse midquote price, volatility, or fragmentation. $D_{i, t}^{C h i-X}$ is a dummy variable equal to one when a stock is traded on Chi-X at that point in time and zero otherwise, and $\alpha_{i}$ and $\gamma_{t}$ are stock and time fixed effects. We estimate (11) on the whole panel and also separately for each stock tercile by volume.

Table 3 reports the estimated effects of Chi-X. The entry of Chi-X is associated with large increases in HFT activity. The increases are statistically significant for both HFT proxies and message traffic in the pooled sample as well as individual volume terciles (with the exception of one of the HFT proxies, HFTtrades $i, t$, in one of the terciles, T2). In the pooled

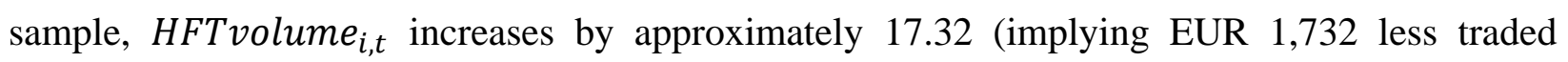
volume per message), which is a large amount given the pooled sample mean of HFTvolume $e_{i, t}$ is -27.46 (implying an average of EUR 2,746 traded volume per message). The entry of Chi-X is also associated with a decrease in volume $\left(d v o l_{i, t}\right)$ in the two highest volume terciles, an increase in volatility, and an increase in fragmentation (as expected).

\section{$<$ Table 3 here $>$}

Next we turn to the impact of HFT on co-movement in returns and in liquidity. For this we use two-stage least squares (2SLS) instrumental variables (IV) panel regressions, similar to 
Hendershot et al. (2011). Because different stocks commence trading on Chi-X at different times, we are able to include stock and time fixed effects in the panel regressions, which effectively gives a difference-in-differences estimator. This eliminates any differences in comovement through time that are unrelated to the level of HFT, as well as time-invariant crosssectional variation in co-movement.

The first-stage regressions are estimated on a panel of stock-day observations:

$$
H F T_{i, t}=\alpha_{i}+\gamma_{t}+\beta D_{i, t}^{\text {Chi-X }}+\sum_{j=1}^{4} \delta_{j} \text { Control }_{j, i, t}+\varepsilon_{i, t} .
$$

We average the fitted values of HFT activity from the first stage for each stock $i$ in each month $\tau$ $\left(\widehat{H F T_{l, \tau}}\right)$ to match the frequency of the co-movement estimates and then use them in the secondstage regressions of stock-month observations:

$$
R_{i, \tau}^{2}=\alpha_{i}+\gamma_{\tau}+\beta \widehat{H F T_{l, \tau}}+\sum_{j=1}^{4} \delta_{j} \text { Control }_{j, i, \tau}+\varepsilon_{i, \tau},
$$

where $H F T_{i, t}$ is one of the proxies for HFT activity, $\alpha_{i}$ and $\gamma_{t}$ are stock and time fixed effects, $D_{i, t}^{C h i-X}$ is a dummy variable equal to one when a stock is traded on Chi-X at that point in time and zero otherwise, and $R_{i, \tau}^{2}$ is one of the co-movement variables (either $R_{i, \tau}^{2, r}$ or $R_{i, \tau}^{2, L I Q}$ ). The set of control variables in both stages comprise measures of fragmentation $\left(F R A G 2_{i, t}\right)$, volume $\left(\right.$ dvol $\left._{i, t}\right)$, volatility ( volatility $\left._{i, t}\right)$, and the inverse of the midquote price (invmidquote int $)$.

Table 4 reports the results from the second-stage regressions. The results show that HFT increases co-movement in both returns and in liquidity. In the pooled sample, the impact of HFT on co-movement is statistically significant at the $1 \%$ level and is stronger than the impact of any of the control variables (fragmentation, volume, volatility, inverse price). In terms of magnitude, the coefficient 7.197 implies that a one-standard-deviation increase in $H_{F T}$ olume $_{i, \tau}$ increases the average return co-movement $\mathrm{R}^{2}$ by 7.13 percentage points, all else equal. ${ }^{13}$ The estimated increase of 7.13 percentage points is meaningful given that the average $\mathrm{R}^{2}$ of the return comovement regressions varies between $24 \%$ and $51 \%$ across countries. The increase is around one-fifth of the pooled sample average return $\mathrm{R}^{2}(41 \%$, Table 2$)$ or around two-fifths of a standard deviation.

The magnitude of the impact of HFT on co-movement in liquidity is even larger. The coefficient 13.481 implies that a one-standard-deviation increase in HFT increases the average

\footnotetext{
13 Since the co-movement estimates are logit transformed $\mathrm{R}^{2}$ values, to provide a meaningful interpretation we perform a reverse transformation similar to Karolyi et al. (2012).
} 
liquidity co-movement $\mathrm{R}^{2}$ by 9.52 percentage points. This increase is around two-fifths of the pooled sample average (23\%, Table 2 ) or around two-thirds of a standard deviation. The results support our hypotheses that HFT increases co-movement.

\section{$<$ Table 4 here $>$}

The impact of HFT is not uniform across terciles. HFT has a significant positive impact on return and liquidity co-movement in the lower two volume terciles and the lower two liquidity terciles, but not the highest tercile (the largest, most liquid, highest volume stocks). The impact of HFT is the strongest in the middle volume tercile, where a standard deviation increase in HFT is associated with an increase of in return co-movement of around 30 percentage points. The impact of HFT on co-movement in liquidity is positive and significant across all volatility terciles, and the impact on co-movement in returns is significant for the two lowest volatility terciles.

One explanation for HFT's stronger impact on co-movement in smaller stocks is from increased monitoring by HFT market makers as the mechanism by which HFT increase comovement. Lyle et al. (2016) show that market makers with limited monitoring capacity (e.g., non-HFT market makers) allocate more effort to monitoring information relevant for the pricing of large stocks in which they face the largest potential losses from having stale quotes picked off. Thus, when monitoring capacity increases due to HFT market makers, there is more scope for improvements in the speed with which quotes in small stocks reflect market-wide information and market-wide liquidity than there is for large stocks. Consistent with this explanation, Chordia et al. (2011) show that information tends to be first incorporated in the prices of large stocks before being transmitted to small stocks. This tendency implies that small stocks have larger potential increases in the speed with which they reflect information and thus their comovement with the market. In support of this notion, Glosten, Nallareddy, and Zou (2016) show that by making it easier to trade on systematic information, the introduction of exchange traded funds (ETFs) increases the speed with which market-wide information is reflect in the prices of small stocks (but not big stocks) thereby increasing their co-movement with the market. It seems from our results that HFTs play a similar role. 
Non-uniformity across terciles in the impact of HFT is also consistent with a habitat effect; an increase in the liquidity of medium and small stocks due to HFT increases the likelihood that they will be held by large institutions and subsequently co-move with other stocks held by institutions. It is also consistent with faster diffusion of market-wide information.

The estimated impacts of HFT on co-movement are qualitatively similar (and therefore not reported) using spreads as the liquidity measure, estimating the models in first differences instead of levels, and permutations of the control variables.

We also examine the effects of HFT on other stock characteristics (returns, liquidity, spreads, and volatility) using the same 2SLS IV approach. Table 5 reports the results. HFT increases liquidity $\left(L I Q_{i, \tau}\right.$, the price impact based measure) and decreases bid-ask spreads. Both of these effects are highly statistically significant, of a meaningful magnitude, and consistent with several other studies that show HFT improves liquidity (e.g., Menkveld, 2013; Hasbrouck and Saar, 2013; Brogaard et al., 2015). For example, the coefficients in Table 5 imply that the increase in HFT activity due to Chi-X results in a decrease in bid-ask spreads of around $61 \mathrm{bps}$, which is close to a $50 \%$ decrease from the pre-Chi-X level of spreads. Consistent with this estimate, Menkveld (2013) shows that spreads in the Dutch market decrease by around 50\% after a HFT market maker starts quoting following the entry of Chi-X. HFT has no significant effect on returns. HFT has a positive effect on volatility (although only marginally statistically significant), which is consistent with the findings of Boehmer et al. (2015) in an international sample. Although Boehmer et al. (2015) focus on the broader category of AT, their empirical design has similarities with ours insomuch as they use speed upgrades (colocation in their case) as instrumental variables.

\section{Analysis of the channels by which HFT impacts co-movement}

The increase in co-movement due to HFT is consistent with a number of possible mechanisms. To get some insight into the relative importance of the different mechanisms, we estimate multiple mediation models and compare the magnitude and significance of various channels (following Preacher and Hayes, 2004, 2008).

One channel through which HFT could increase co-movement in returns is through correlated trading across stocks (e.g., Chaboud et al., 2014; Bias and Wooley, 2011; Boehmer et al., 2018), similar to what has been previously documented for quant funds. Jarrow and Protter 
(2012) point out that opportunistic HFTs can increase systematic return variation and have a destabilizing effect when they unknowingly coordinate on a common signal.

A second channel is by increasing the speed with which prices reflect public market-wide information (e.g., Brogaard et al., 2014a; Carrion, 2013). Barberis et al. (2005), in what they refer to as the "information diffusion view", argue that market-wide information is reflected in the prices of different stocks at different rates. An increase in the synchronicity with which individual stocks reflect market-wide information therefore increases co-movement. Such an increase in synchronicity could arise if, for example, HFT increase the speed with which marketwide information is transmitted from large stocks to small stocks, which is consistent with our finding that smaller stocks tend to have the largest increase in co-movement. Disentangling the information diffusion channel from the correlated HFT trading channel is important because increased co-movement from faster information diffusion is beneficial in that it reduces pricing errors, whereas increased co-movement for other reasons can increase systematic risk.

We account for a third channel, which is that the increase in liquidity due to HFT activity (recall spreads fall by close to $50 \%$ as a result of HFT activity following the entry of Chi-X) makes medium and small stocks more attractive to other non-HFT participants, in particular large institutional investors that are limited to investing in highly liquid stocks. Prior studies find that a stock's co-movement with the market increases when it is added to a market index and at least part of this increase is due to the increase in holdings by large investors (e.g., Barberis et al., 2005). In what they refer to as the "habitat view", Barberis et al. (2005) argue that investors hold subsets of stocks (due to transaction costs, information constraints, and so on). When the risk aversion, sentiment, or liquidity needs of investors change, they tend to trade their holdings in a similar manner, creating a common factor in the given subsets of stocks. An increase in stock liquidity makes it more likely that the stock becomes part of the "habitat" of large investors and therefore that the stock will co-move with other stocks held by large institutions.

The distinguishing features of these three channels are that the information diffusion channel implies the causal chain $\uparrow \mathrm{HFT}=>\downarrow$ delay in prices $=>\uparrow$ return co-movement, whereas the habitat view implies the causal chain $\uparrow$ HFT $=>\uparrow$ liquidity $=>\uparrow$ return co-movement, and the correlated trading channel implies a direct effect $(\uparrow H F T=>\uparrow$ return co-movement) that does not occur through $\downarrow$ delay in prices or through $\uparrow$ liquidity. Mediation analysis can quantify the role of each of these channels. We measure the delay with which prices reflect market-wide 
information ("delay in prices") using the method developed by Hou and Moskowitz (2005). The approach involves estimating two regressions of individual stock returns on market returns:

$$
\begin{gathered}
r_{i, t}=\alpha_{i}+\beta_{i} r_{m, t}+\varepsilon_{i, t} \\
r_{i, t}=\alpha_{i}+\sum_{j=0}^{4} \beta_{i, j} r_{m, t-j}+\varepsilon_{i, t}^{r}
\end{gathered}
$$

and saving the two $\mathrm{R}^{2}$ values as $R_{i, \tau}^{2, R E S T R I C T E D}$ and $R_{i, \tau}^{2, U N R E S T R I C T E D}$, respectively. ${ }^{14}$ Whenever market-wide information is not instantly and fully reflected in the returns of individual stocks, the $\mathrm{R}^{2}$ from the first regression (which includes only the contemporaneous market return) will be less than the $\mathrm{R}^{2}$ of the second regression (which includes contemporaneous and lagged market returns). The difference between the $\mathrm{R}^{2}$ values is the extent to which market-wide information is impounded in prices with a delay. The delay metric is therefore:

$$
\text { delay }_{i, \tau}=1-\frac{R_{i, \tau}^{2, R E S T R I C T E D}}{R_{i, \tau}^{2, U N R E S T R I C T E D}} .
$$

We use the serial multiple mediator model of Hayes (2012) and Preacher and Hayes (2004, 2008). The general idea behind these mediation models is estimating a series of regressions involving various permutations of the independent, mediator, and dependent variables and combining the outcomes to infer the direct and mediated channels by which the independent variable affects the dependent variable. The procedure ensures all the channels sum to the total effect of the independent variable on he dependent variable. Hayes (2012) and Preacher and Hayes $(2004,2008)$ provide the relevant statistics for testing the significance of the various channels and for expressing the strength of a mediated channel as a proportion of the total effect. The intuition for how a mediation channel is identified from a series of regressions (in the simple case of a single mediator) is that if a mediating relation exists the following three results will hold: (i) the independent variable affects the mediator in a regression of the mediator on the independent variable; (ii) the independent variable affects the dependent variable in a regression of the dependent variable on the independent variable; and (iii) the mediator and not the independent variable affects the dependent variable in a regression of the dependent variable on both the independent and mediator variables.

Fig. 4 illustrates the results of the multiple mediation models for the drivers of return comovement. The coefficient estimates support the existence of all three channels. However, the channels differ in importance. Approximately one-third (35.1\%) of the impact of HFT on return

\footnotetext{
${ }^{14} \mathrm{We}$ estimate these regressions separately for each stock in each month using daily observations.
} 
co-movement occurs through faster diffusion of market-wide information, consistent with the evidence that HFT facilitate price discovery (e.g., Brogaard et al., 2014a). That leaves around two-thirds of the increase in return co-movement to other channels, which potentially increases systematic risk. Only $9.0 \%$ of the total effect occurs through the effect of HFT on liquidity. Thus, there is some support for the habitat view as a channel by which HFT increase comovement in returns, but this channel is not strong relative to the other mechanisms. That leaves $55.9 \%$ of the effect of HFT on return co-movement as a direct effect. Given our discussion of the ways that HFT might impact co-movement, most of this direct effect is likely due to correlated trading strategies of HFT. This finding is consistent with Hasbrouck and Seppi (2001) who show that co-movement in returns is largely driven by co-movement in order flows.

$<$ Fig. 4 here >

Turning to HFT's impact on co-movement in liquidity, one channel is the "habitat" effect described earlier. The increase in liquidity resulting from HFT market making can attract a clientele of large institutional investors. When such investors trade into or out of positions in a correlated manner (e.g., due to fund flows) they can create an additional source of liquidity comovement. Its distinguishing feature is the mediating role played by the level of liquidity: $\uparrow$ HFT $=>\uparrow$ liquidity $=>\uparrow$ liquidity co-movement.

A second channel is associated with HFT's effect on volatility (which we find to be positive and significant in Table 5). Kamara, Lou, and Sadka (2008) report that market-wide volatility creates similar trading behavior among traders and hence affects liquidity comovement. Similarly Karolyi et al. (2012) find higher liquidity co-movement when volatility is higher. More specific to HFT, although HFT market makers increase liquidity on average, their lack of a binding commitment such as an affirmative obligation in providing liquidity means the liquidity they provide can be a source of fragility and subject to sharp withdrawals when conditions become unfavorable. Anand and Venkataraman (2016) show that "endogenous liquidity providers" (many of which are HFTs) scale back in unison when conditions are unfavorable. Such behavior creates additional volatility, and can increase liquidity comovement. This destabilizing liquidity provision can even contribute to extreme events such as 
flash crashes (Kirilenko et al., 2017). This channel is identified through the proportion of the increase in liquidity co-movement that is associated with increased volatility.

Finally, there are reasons why HFT can increase liquidity co-movement directly rather than through mediating variables. One such reason is HFT's enhanced ability to monitor conditions in a broader cross-section of stocks and adjust their liquidity provision accordingly. Cespa and Foucault (2014) model this mechanism and show that it gives rise to cross-asset liquidity spillovers that can increase liquidity co-movement. Similarly, correlated trading of opportunistic HFTs can increase liquidity co-movement when they demand liquidity in aa number of stocks simultaneously (e.g., statistical arbitrage strategies).

We again use multiple mediation models to tease apart the mediated channels from the direct channels. Fig. 5 illustrates the results. We find support for both of the indirect (mediated) channels as well as the direct channel-all three channels are statistically significant. Similar to the results for return co-movement, the habitat effect is small in magnitude, accounting for only $5.1 \%$ of the total effect of HFT on liquidity co-movement. The volatility channel is larger, accounting for around one-fifth of the total effect $(18.8 \%)$. The remaining three-quarters of the effect of HFT on liquidity co-movement is direct (76\%). Therefore, the results suggest HFT market makers' enhanced ability to monitor prices and conditions in a broad cross-section of stocks as well as correlated trading by opportunistic HFTs are likely to be the main drivers of HFTs' impact on liquidity commonality. This conclusion is consistent with Koch et al. (2016) who find that co-movement in liquidity is driven by traders with similar trading behavior and inventories and Bai and Qin (2010) who find that systematic liquidity risk arises from correlated trading behavior of investors.

\section{$<$ Fig. 5 here $>$}

It is useful to compare our results with those of Boehmer et al. (2018). Boehmer et al. (2018) identify three major groups of strategies used by HFT firms - market making, crossmarket arbitrage, and directional strategies. They show that competition among HFT firms, in particular among market making HFTs, tends to decrease one-second trade price volatility, which can be interpreted as an increase in liquidity. This overall result is consistent with our finding that liquidity improves with more HFT. While Boehmer et al. (2018) do not analyze the 
impact of HFT on co-movement in returns and in liquidity, some of the mechanisms that they suggest as drivers of the improved liquidity imply that HFTs increase co-movement and we find support for these mechanisms. For example, Boehmer et al. (2018) argue that the decrease in adverse selection associated with strong competition among HFTs could be because HFTs are better able to extract signals from related securities and from the market index. This conjecture is supported by our finding that HFTs reduce the delay with which market-wide information is reflected in stock prices, leading to an increase in return co-movement. Furthermore, Boehmer et al. (2018) argue that the reductions in temporary price impacts and realized spreads associated with strong competition among market making HFTs could be due to decreasing rents from market making. Such competition limits the ability for market makers to cross-subsidize liquidity provision in adverse conditions with rents from liquidity provision in favorable conditions. Consequently HFT market makers enter and exit in a correlated manner depending on market conditions (e.g., Anand and Venkataraman, 2016), resulting in increased comovement in liquidity. Our results also support this mechanism.

Therefore, the tendency for HFT to increase both the level of liquidity and the extent of co-movement in returns and in liquidity is related-both effects share several common mechanisms / drivers. This finding reiterates the importance of considering the impact of HFT on co-movement when assessing the overall effects of HFT because the increase in co-movement due to HFT, at least in part, is jointly determined with the increased liquidity due to HFT. Considering the effects of HFT on only the level of liquidity can overstate the benefits of HFT.

We examine the sensitivity of the mediation results to changes in the model specification. We test the effects of removing the control variables, using a different set of control variables, and removing the liquidity channel (which is the weakest of the channels), thereby changing the model structure. We find that the results are qualitatively similar across the different model specifications. There are some changes to the relative importance of the different channels when omitting or changing the set of control variables and these changes could be due to an omitted variables bias in the alternative model specifications. ${ }^{15}$

\footnotetext{
${ }^{15}$ The results of these robustness tests are in the Online Appendix, Section 4.
} 


\section{The effects of HFT in different market conditions}

Our sample period spans a period of relatively calm, "normal" market conditions and a crisis period (the years 2008-2009) in which the market fell sharply and volatility was relatively high. In our main analysis, we remove the effects of the crisis on the level of co-movement by using difference-in-differences models. However, the effects of HFT on co-movement and other market characteristics could depend on market conditions. For example, the increased volatility during the crisis years might cause HFTs to provide less liquidity, or to more often withdraw their liquidity in response to adverse conditions, or to more often take liquidity to exploit arbitrage opportunities.

To explore these possibilities, we re-estimate our models allowing the effects of HFT in the crisis period to be different to those in the pre-crisis period. The full set of results is in the Online Appendix Section 3; here we summarize the findings.

First, we find that the sign and magnitude of the effect of HFT on return/liquidity comovement is similar in the pre-crisis and crisis periods. In fact, the difference in HFT's effects in the two periods is not statistically distinguishable from zero, and is small in magnitude (less than $10 \%$ difference). Thus, the overall tendency for HFT to increase co-movement in returns and in liquidity holds in normal and in high volatility conditions. This finding is not completely surprising given the main channels by which HFT increase co-movement include faster price discovery, correlated trading strategies, and better ability to monitor other stocks-these effects are present in both normal and stressed/volatile market conditions.

In contrast, we find that the effects of HFT on liquidity, and the channels by which HFT affects co-movement in liquidity, do depend on market conditions. HFT are more beneficial to liquidity during the pre-crisis period than during the crisis, although their crisis-period effect on liquidity remains positive. Other studies find that aggregate liquidity decreases during market declines because capital constraints in the market making sector become binding (e.g., Brunnermeier and Pedersen, 2009; Hameed et al., 2010; Comerton-Forde et al., 2010). Because many HFTs engage in market making (e.g., Hagströmer and Nordén, 2013), our finding is consistent with the notion that HFTs also face capital constraints that become more binding during periods of declining prices and high volatility.

Furthermore, we find that a larger proportion of the effect of HFT on liquidity comovement during the crisis is associated with increased volatility. This result is consistent with 
recent findings that HFT withdraw their liquidity from a number of stocks in unison when conditions become unfavorable (e.g., Anand and Venkataraman, 2016), and the fact that unfavorable conditions such as high volatility occur more often during crises. High volatility is disliked by market makers because it increases the risk of holding inventory positions. The effects of HFT on liquidity co-movement are also consistent with earlier studies of the determinants of variation in liquidity. For example, Brunnermeier and Pedersen (2009) show that market maker capital constraints drive liquidity co-movement and Hameed et al. (2010) show that the co-movement in liquidity that is induced by capital constraints becomes stronger during market declines. In this regard, HFTs exhibit similar attributes as other market makers.

Taken together, our findings comparing the pre-crisis and crisis period effects of HFT provide support to the concerns expressed by some market participants and regulators that HFTs provide less liquidity during times of market stress, which is precisely when the market needs the liquidity the most. Further, our findings suggest that this tendency of HFTs affects not only the amount of liquidity they provide, but also contributes to commonality in liquidity, which is a type of liquidity risk. Such risk is likely to affect asset prices ex-ante as investors demand higher rates of return as compensation for such risk (e.g., Acharya and Pedersen, 2005). Our finding that the effects of HFT are somewhat different during crisis and non-crisis periods supports the idea of incorporating asymmetric dependence into asset pricing models, allowing the relations between individual stock liquidity, market-wide liquidity, and returns to vary with market conditions (e.g., Anthonisz and Putniņš, 2017).

\section{Conclusion}

Our main finding is that HFT increases co-movement in both returns and in liquidity. We establish causality by exploiting the staggered entry of Chi-X in 12 European equity markets. The positive effect of HFT on co-movement is economically meaningful. A one-standarddeviation increase in HFT increases return co-movement by one-fifth of its mean and liquidity co-movement by two-fifths of its mean.

The impact of HFT is not uniform across stocks; medium and small stocks (by volume and liquidity) experience larger increases in co-movement. The stronger impact on medium and small stocks is consistent with the notion that prior to HFT, liquidity providers with limited monitoring capacity allocated relatively less effort to monitoring information relevant for small 
stocks, where the stakes are lower. The increase in monitoring capacity brought about by HFT therefore disproportionately increases monitoring of value-relevant information about medium and small stocks, thereby increasing their synchronicity with the rest of the market. The nonuniformity in the impact of HFT on co-movement is also consistent with a habitat effect; an increase in the liquidity of medium and small stocks due to HFT increases the likelihood that they will be held by large institutions and subsequently co-move with other stocks held by institutions.

We also examine the effects of HFT on other stock characteristics. Consistent with other studies, we find that HFT increases liquidity measured by Amihud's price impact metric and bidask spreads. The increases in liquidity are economically meaningful; for example, spreads decrease by almost one-half. HFT is more beneficial to liquidity during "normal" periods than during the crisis years (2008-2009) when volatility is high. Our results also suggest that HFT are associated with increased volatility.

HFTs' impact on co-movement occurs for a number of reasons. We estimate that around one-third of the increase in co-movement in returns is due to faster diffusion of market-wide information. We attribute the other two-thirds of the increase in return co-movement to correlated trading strategies of HFTs, and to a lesser extent a habitat effect whereby large institutional investors are able to hold smaller stocks than previously due to the increased liquidity. Similarly, we find that the habitat effect explains only a relatively small fraction of the increase in liquidity co-movement. The tendency for HFT liquidity providers to withdraw from the market when conditions are unfavorable is a source of fragility that increases both volatility and co-movement in liquidity. This effect is particularly pronounced during high volatility, such as during 2008-2009. We estimate this component accounts for around one-fifth of the increase in liquidity co-movement. Our results suggest the main drivers of the increase in liquidity comovement are the increased ability of HFT market markers to monitor conditions in other stocks and the correlated liquidity demand of opportunistic HFTs.

Our results help paint a more complete picture of the effects of HFT, showing that some of the benefits of HFT, such as increased liquidity, are somewhat offset by an increase in comovement. Co-movement affects the way shocks are transmitted between stocks and thus the level of systemic risk. Higher co-movement also has implications for the cost of capital and thus investment by firms and the real economy. Asset pricing models show that co-movement in 
returns and in liquidity is associated with cross-sectional return premiums that increase the cost of capital. However, because HFT also increase the level of liquidity (which will tend to lower the cost of capital), HFT have two opposing effects on the costs of capital. Which one dominates is an important empirical question that is left for future work. 


\section{Appendix}

\section{Table A1}

List of trading venues for which we consolidate data

This table lists the trading venues for which we consolidate trades and quotes for our sample of stocks from 12 countries.

\begin{tabular}{llll}
\hline Exchange name & Country & Exchange name & Country \\
\hline Vienna SE & Austria & Euronext Amsterdam & Netherlands \\
Euronext Brussels & Belgium & Burgundy MTF & Nordic Region \\
Prague SE & Czech Republic & Oslo SE & Norway \\
Nasdaq OMX Copenhagen & Denmark & Warsaw SE & Poland \\
NYSE ARCA & Europe & Euronext Lisbon & Portugal \\
Sigma X & Europe & Bucharest SE & Romania \\
Nasdaq OMX Helsinki & Finland & Russian Trading System & Russia \\
MONEP & France & Saudi SE & Saudi Arabia \\
Euronext Paris & France & Barcelona SE & Spain \\
Berlin SE & Germany & Bilbao SE & Spain \\
RWB & Germany & Madrid SE & Spain \\
Xetra & Germany & Mercado Continuo & Spain \\
Frankfurt SE & Germany & Valencia SE & Spain \\
Hamburg SE & Germany & Nordic Growth Market & Sweden \\
Hanover SE & Germany & Nasdaq OMX Stockholm & Sweden \\
Munich SE & Germany & Berne SE & Switzerland \\
Stuttgart SE & Germany & Scoach Switzerland & Switzerland \\
TradeGate SE & Germany & Swiss Blue Chip Segment & Switzerland \\
Xetra International Market & Germany & Istanbul SE & Turkey \\
Budapest SE & Hungary & Equiduct & United Kingdom \\
Quote MTF Ltd & Hungary & BATS Europe & United Kingdom \\
Irish SE & Ireland & Channel Islands SE & United Kingdom \\
Tel Aviv SE & Israel & Chi-X Europe & United Kingdom \\
Milan SE & Italy & London SE & United Kingdom \\
Euro TLX & Italy & PLUS Markets Group & United Kingdom \\
Luxembourg SE & Luxembourg & Turquoise & United Kingdom \\
& & & \\
\hline & & & \\
\hline
\end{tabular}




\section{References}

Acharya, V.V., L.H. Pedersen, 2005. Asset pricing with liquidity risk. Journal of Financial Economics 77, 375-410.

Ait-Sahalia, Y., M. Saglam, 2013. High frequency traders: taking advantage of speed. Unpublished working paper.

Amihud, Y., 2002. Illiquidity and stock returns: cross-section and time-series. Journal of Financial Markets 5, 31-56.

Amihud, Y., H. Mendelson, 1986. Asset pricing and the bid-ask spread, Journal of Financial Economics 17, 223-249.

Anand, A., K. Venkataraman, 2016. Market conditions, fragility and the economics of market making. Journal of Financial Economics 121, 327-349.

Anthonisz, S., T.J. Putniņš, 2017. Asset pricing with downside liquidity risks. Management Science 63, 2549-2572.

Bai, M., Y. Qin, 2010. Who are driving commonality in liquidity? Global Economy and Finance Journal 3, 61-77.

Barberis, N., A. Shleifer, J. Wurgler, 2005. Comovement. Journal of Financial Economics 75, 283-317.

Bartram, S., G. Brown, R. Stulz, 2012. Why are US stocks more volatile? Journal of Finance 67, 1334-1370.

Bennett, P., L. Wei, 2006. Market structure, fragmentation, and market quality. Journal of Financial Markets 9, 49-78.

Biais, B., T. Foucault, S. Moinas, 2015. Equilibrium fast trading. Journal of Financial Economics 73, 3-36.

Biais B., P. Woolley, 2011. High frequency trading. Unpublished working Paper.

Boehmer, E., K. Fong, J. Wu, 2015. International evidence on algorithmic trading. Unpublished working paper.

Boehmer, E., D. Li, G. Saar, 2018. The competitive landscape of high-frequency trading firms. Review of Financial Studies (forthcoming).

Brockman, P., D.Y. Chung, C. Pérignon, 2009. Commonality in liquidity: a global perspective. Journal of Financial and Quantitative Analysis 44, 851-882. 
Brogaard, J., B. Hagströmer, L. Nordèn, R. Riordan, 2015. Trading fast and slow: colocation and market quality. Review of Financial Studies 28, 3407-3443.

Brogaard, J., T. Hendershott, S. Hunt, C. Ysusi, 2014b. High-frequency trading and the execution costs of institutional investors. Financial Review 49, 345-369.

Brogaard, J., T. Hendershott, R. Riordan, 2014a. High-frequency trading and price discovery. Review of Financial Studies 27, 2267-2306.

Brogaard, J., T. Hendershott, R. Riordan, 2017. High frequency trading and the 2008 short-sale ban. Journal of Financial Economics 124, 22-42.

Campbell, J., M. Lettau, B. Malkiel, Y. Xu, 2001. Have individual stocks become more volatile? An empirical exploration of idiosyncratic risk. Journal of Finance 56, 1-43.

Carrion, A., 2013. Very fast money: high-frequency trading on the NASDAQ. Journal of Financial Markets 16, 680-711.

Cespa, G., T. Foucault, 2014. Illiquidity contagion and liquidity crashes. Review of Financial Studies 27, 1615-1660.

Chaboud, A., B. Chiquoine, E. Hjalmarsson, C. Vega, 2014. Rise of the machines: algorithmic trading in the foreign exchange market. Journal of Finance 69, 2045-2084.

Chan, K., A. Hameed, 2006. Stock price synchronicity and analyst coverage in emerging markets. Journal of Financial Economics 80, 115-147.

Chordia, T., R. Roll, A. Subrahmanyam, 2000. Commonality in liquidity. Journal of Financial Economics 56, 3-28.

Chordia, T., A. Goyal, B.N. Lehmann, G. Saar, 2013. Editorial: high-frequency trading. Journal of Financial Markets 16, 637-645.

Chordia, T., A. Sarkar, A. Subrahmanyam, 2011. Liquidity dynamics and cross-autocorrelations. Journal of Financial and Quantitative Analysis 46, 709-736.

Claessens, S., Y. Yafeh, 2012. Comovement of newly added stocks with national market indices: evidence from around the world. Review of Finance 17, 203-227.

Comerton-Forde, C., T. Hendershott, C.M. Jones, P.C. Moulton, M.S. Seasholes, 2010. Time variation in liquidity: the role of market-maker inventories and revenues. Journal of Finance 65, 295-331.

Degryse, H., F. de Jong, V. van Kervel, 2015. The impact of dark trading and visible fragmentation on market quality. Review of Finance 19, 1587-1622. 
Dimson, E., 1979. Risk measurement when shares are subject to infrequent trading. Journal of Financial Economics 7, 197-226.

Durnev, A., R. Morck, B. Yeung, P. Zarowin, 2003. Does greater firm-specific return variation mean more or less informed stock pricing? Journal of Accounting Research 41, 797-836.

Foucault, T., 2012. Algorithmic trading: issues and preliminary evidence. In: Abergel, F., J.P. Bouchaud, T. Foucault, C.A. Lehalle, M. Rosenbaum (Eds.), Market Microstructure: Confronting Many Viewpoints. John Wiley \& Sons, New York, pp. 3-39.

Foucault, T., J. Hombert, I. Roşu, 2016. News trading and speed. Journal of Finance 71, 335382.

Glosten, L., S. Nallareddy, Y. Zou, 2016. ETF trading and informational efficiency of underlying securities, Unpublished working Paper.

Goyenko, R.Y., C.W. Holden, C.A. Trzcinka, 2009. Do liquidity measures measure liquidity? Journal of Financial Economics 92, 153-181.

Hameed, A., W. Kang, S. Viswanathan, 2010. Stock market declines and liquidity. Journal of Finance 65, 257-293.

Hasbrouck, J., 2009. Trading costs and returns for U.S. equities: estimating effective costs from daily data. Journal of Finance 64, 1445-1477.

Hasbrouck, J., G. Saar, 2013. Low-latency trading. Journal of Financial Markets 16, 646-679.

Hasbrouck, J., D.J. Seppi, 2001. Common factors in prices, order flows and liquidity. Journal of Financial Economics 59, 383-411.

Hayes, A.F., 2012. Process: a versatile computational tool for observed variable mediation, moderation, and conditional process modeling. Unpublished working paper.

Hendershott, T., R. Riordan, 2013. Algorithmic trading and the market for liquidity. Journal of Financial and Quantitative Analysis 8, 1001-1024.

Hendershott, T., C.M. Jones, A.J. Menkveld, 2011. Does algorithmic trading improve liquidity? Journal of Finance 66, 1-33.

Hou, K., T.J. Moskowitz, 2005. Market frictions, price delay, and the cross-section of expected returns. Review of Financial Studies 18, 981-1020.

Huberman, G., D. Halka, 2001. Systematic liquidity. Journal of Financial Research 24, 161-178.

Hutton, A., A. Marcus, H. Tehranian, 2009. Opaque financial reports, $\mathrm{R}^{2}$, and crash risk. Journal of Financial Economics 94, 67-86. 
Jarrow, R.A., P. Protter, 2012. A dysfunctional role of high frequency trading in electronic markets. International Journal of Theoretical and Applied Finance 15, 219-249.

Jin, L., S. Myers, 2006. R-squared around the world: new theory and new tests. Journal of Financial Economics 79, 257-292.

Jovanovic, B., A.J. Menkveld, 2016. Middlemen in limit order markets. Unpublished working paper.

Kamara, A., X. Lou, R. Sadka, 2008. The divergence of liquidity commonality in the crosssection of stocks. Journal of Financial Economics 89, 444-466.

Karolyi, G.A., K. Lee, M.A. Dijk, 2012. Understanding commonality in liquidity around the world. Journal of Financial Economics 105, 82-112.

Khandani, A., A. Lo, 2011. What happened to the Quants in August 2007? Evidence from factors and transactions data. Journal of Financial Markets 14, 1-46.

Kirilenko, A., A.S. Kyle, M. Samadi, T. Tuzun, 2017. The Flash Crash: High frequency trading in an electronic market. Journal of Finance 72, 967-998.

Koch, A., S. Ruenzi, L.T. Starks, 2016. Commonality in liquidity: a demand-side explanation. Review of Financial Studies 29, 1943-1974.

Lyle, M.R., J.P. Naughton, B.M. Weller, 2016. How does algorithmic trading improve market quality? Unpublished working paper.

Menkveld, A.J., 2013. High frequency trading and the new-market makers. Journal of Financial Markets 16, 712-740.

Menkveld, A.J., 2016. The economics of high-frequency trading: taking stock. Annual Review of Financial Economics 8, 1-24.

Morck, R., B. Yeung, W. Yu, 2000. The information content of stock markets: why do emerging markets have synchronous stock price movements? Journal of Financial Economics 58, $215-260$.

Preacher, K.J., A.F. Hayes, 2004. SPSS and SAS programming for the testing of mediation models. Behavior Research Methods, Instruments, Computers 36, 717-731.

Preacher, K.J., A.F. Hayes, 2008. Asymptotic and resampling strategies for assessing and comparing indirect effects in multiple mediator models. Behavior Research Methods 40, 879-891. 
Riordan, R., A. Storkenmaier, 2012. Latency, liquidity and price discovery. Journal of Financial Markets 5, 416-437.

Roll, R., 1988. R². Journal of Finance 43, 541-566.

Scholes, M., J. Williams, 1977. Estimating betas from nonsynchronous data. Journal of Financial Economics 5, 309-327. 
Table 1

Definitions of variables and descriptive statistics

This table defines the variables calculated for each stock-day, $i, t$, and reports descriptive statistics. The sample comprises 1,311 stocks from 12 European countries and spans the period February 1, 2007 to February 27, 2009, with a total of 674,307 stock-day observations. Means of variables are calculated for the full sample (Pooled) as well as terciles of stocks based on EUR volume. Terciles are constructed using country-specific breakpoints to ensure terciles are similar in the distribution of stocks from each country. $T 1$ (T3) contains stocks with the lowest (highest) average daily traded EUR volume during the sample period. The standard deviation $(S D)$ is calculated within time, $x_{i, t}^{*}=x_{i, t}-\bar{x}_{i}$.

\begin{tabular}{|c|c|c|c|c|c|c|}
\hline Variable & Description & $\begin{array}{l}\text { Mean } \\
\text { Pooled }\end{array}$ & $\begin{array}{c}\text { Mean } \\
\text { T1 }\end{array}$ & $\begin{array}{l}\text { Mean } \\
\text { T2 }\end{array}$ & $\begin{array}{c}\text { Mean } \\
\text { T3 }\end{array}$ & $\begin{array}{c}\text { SD } \\
\text { within }\end{array}$ \\
\hline$r_{i, t}$ & $\begin{array}{l}\text { Daily midquote return using consolidated } \\
\text { quotes (bps) }\end{array}$ & -20.83 & -18.92 & -22.45 & -21.06 & 472.58 \\
\hline$L I Q_{i, t}$ & $\begin{array}{l}\text { Price impact based liquidity measure, } \\
\text { calculated as the negative log of } \\
\text { Amihud's ILLIQ (absolute return divided } \\
\text { by traded EUR volume) }\end{array}$ & -0.38 & -0.83 & -0.34 & -0.03 & 0.63 \\
\hline spread $_{i, t}$ & $\begin{array}{l}\text { Time-weighted relative quoted spread for } \\
\text { stock } i \text { in the consolidated order book } \\
\text { (bps) }\end{array}$ & 111.69 & 240.03 & 76.13 & 18.30 & 438.41 \\
\hline spread $_{i, t}^{\text {home }}$ & $\begin{array}{l}\text { Time-weighted relative quoted spread for } \\
\text { stock } i \text { on its home exchange (bps) }\end{array}$ & 125.30 & 275.19 & 84.82 & 20.47 & 536.01 \\
\hline $\operatorname{spread}_{i, t}^{\text {ChiX }}$ & $\begin{array}{l}\text { Time-weighted relative quoted spread for } \\
\text { stock } i \text { on Chi-X (bps) }\end{array}$ & 79.30 & 137.85 & 101.16 & 50.40 & 83.57 \\
\hline trades $_{i, t}$ & $\begin{array}{l}\text { Daily number of trades in stock } i \\
\text { consolidated across all venues }\end{array}$ & $1,468.67$ & 195.10 & 709.07 & $3,555.90$ & $1,401.25$ \\
\hline trades $s_{i, t}^{\text {home }}$ & $\begin{array}{l}\text { Daily number of trades in stock } i \text { on its } \\
\text { home exchange }\end{array}$ & $1,282.01$ & 186.17 & 663.17 & $3,042.59$ & $1,070.22$ \\
\hline trades $_{i, t}^{\text {Chix }}$ & $\begin{array}{l}\text { Daily number of trades in stock } i \text { on Chi- } \\
\mathrm{X}\end{array}$ & 91.70 & 1.47 & 21.86 & 255.87 & 421.57 \\
\hline messages $_{i, t}$ & $\begin{array}{l}\text { Daily number of quote messages (' } 000 \text { ) } \\
\text { in stock } i \text { 's consolidated order book (a } \\
\text { proxy for HFT activity) }\end{array}$ & 17.15 & 2.39 & 8.02 & 41.66 & 37.56 \\
\hline messages home $_{i, t}^{\text {home }}$ & $\begin{array}{l}\text { Daily number of quote messages ('000) } \\
\text { for stock } i \text { on its home exchange }\end{array}$ & 6.30 & 1.15 & 3.49 & 14.46 & 7.51 \\
\hline $\operatorname{messages}_{i, t}^{\text {ChiX }}$ & $\begin{array}{l}\text { Daily number of quote messages (' } 000 \text { ) } \\
\text { for stock } i \text { on Chi-X }\end{array}$ & 2.92 & 0.20 & 1.09 & 7.59 & 13.61 \\
\hline HFTvolume $_{i, t}$ & $\begin{array}{l}\text { Negative trading volume (' } 00 \text { EUR) } \\
\text { scaled by the number of quote messages, } \\
\text { consolidated across all venues (a proxy } \\
\text { for HFT) }\end{array}$ & -27.46 & -21.34 & -19.10 & -42.09 & 52.49 \\
\hline HFTvolume $e_{i, t}^{\text {home }}$ & $\begin{array}{l}\text { Negative trading volume ('00 EUR) } \\
\text { scaled by the number of quote messages, } \\
\text { in the stock's home exchange }\end{array}$ & -41.38 & -26.70 & -29.12 & -68.17 & 170.14 \\
\hline HFTvolume ${ }_{i, t}^{\text {Chix }}$ & $\begin{array}{l}\text { Negative trading volume ('00 EUR) } \\
\text { scaled by the number of quote messages, } \\
\text { in Chi-X }\end{array}$ & -1.52 & -0.24 & -0.92 & -2.43 & 4.35 \\
\hline HFTtrades $_{i, t}$ & $\begin{array}{l}\text { Daily number of quote messages scaled } \\
\text { by the number of daily trades, } \\
\text { consolidated across all venues (a proxy } \\
\text { for HFT) }\end{array}$ & 18.25 & 25.88 & 17.77 & 11.78 & 69.36 \\
\hline HFTtrades $_{i, t}^{\text {home }}$ & $\begin{array}{l}\text { Daily number of quote messages scaled } \\
\text { by the number of daily trades, in the } \\
\text { stock's home exchange }\end{array}$ & 17.26 & 29.81 & 12.53 & 10.85 & 151.77 \\
\hline HFTtrades $_{i, t}^{\text {ChiX }}$ & $\begin{array}{l}\text { Daily number of quote messages scaled } \\
\text { by the number of daily trades, in Chi-X }\end{array}$ & 192.34 & 327.19 & 296.14 & 106.72 & $1,937.74$ \\
\hline
\end{tabular}


Table 1 - Continued

\begin{tabular}{|c|c|c|c|c|c|c|}
\hline Variable & Description & $\begin{array}{l}\text { Mean } \\
\text { Total }\end{array}$ & $\begin{array}{c}\text { Mean } \\
\text { T1 }\end{array}$ & $\begin{array}{c}\text { Mean } \\
\text { T2 }\end{array}$ & $\begin{array}{c}\text { Mean } \\
\text { T3 }\end{array}$ & $\begin{array}{c}\text { SD } \\
\text { within }\end{array}$ \\
\hline$d v o l_{i, t}$ & $\begin{array}{l}\text { Daily traded EUR volume, consolidated across } \\
\text { all venues (EUR million) }\end{array}$ & 33.20 & 1.52 & 8.12 & 91.42 & 45.61 \\
\hline$d v o l_{i, t}^{\text {home }}$ & $\begin{array}{l}\text { Daily traded EUR volume in the stock's home } \\
\text { exchange (EUR million) }\end{array}$ & 28.24 & 1.40 & 7.35 & 77.20 & 38.52 \\
\hline$d v o l_{i, t}^{C h i x}$ & $\begin{array}{l}\text { Daily traded EUR volume in Chi-X (EUR } \\
\text { million) }\end{array}$ & 0.67 & 0.004 & 0.096 & 1.93 & 3.77 \\
\hline$F R A G 1_{i, t}$ & $\begin{array}{l}\text { Fragmentation proxy } \# 1 \text {, calculated as the } \\
\text { number of venues that execute trades during that } \\
\text { stock-day }\end{array}$ & 3.57 & 1.99 & 2.97 & 5.80 & 1.77 \\
\hline$F R A G 2_{i, t}$ & $\begin{array}{l}\text { Fragmentation proxy } \# 2 \text {, calculated as the } \\
\text { Herfindahl-Hirschman index of traded EUR } \\
\text { volume in each venue }\end{array}$ & 0.07 & 0.05 & 0.06 & 0.11 & 0.10 \\
\hline$F R A G 3_{i, t}$ & $\begin{array}{l}\text { Fragmentation proxy } \# 3 \text {, calculated as the } \\
\text { Herfindahl-Hirschman index of the number of } \\
\text { trades in each venue }\end{array}$ & 0.07 & 0.05 & 0.05 & 0.10 & 0.10 \\
\hline$F R A G 4_{i, t}$ & $\begin{array}{l}\text { Fragmentation proxy } \# 4 \text {, calculated as the EUR } \\
\text { volume market share of all venues other than the } \\
\text { home market ( } 0 \text { to } 1)\end{array}$ & 0.08 & 0.08 & 0.06 & 0.10 & 0.13 \\
\hline invmidquote $_{i, t}$ & $\begin{array}{l}\text { Inverse of the midquote for the consolidated } \\
\text { order book at } 4: 30 \mathrm{pm} \text { GMT }\end{array}$ & 0.26 & 0.36 & 0.27 & 0.14 & 0.41 \\
\hline volatility $_{i, t}$ & $\begin{array}{l}\text { Standard deviation of hourly intraday midquote } \\
\text { returns (bps) }\end{array}$ & 76.65 & 79.53 & 70.22 & 80.32 & 169.13 \\
\hline
\end{tabular}


Table 2

Descriptive statistics on co-movement and market variables for all countries and terciles

This table reports descriptive statistics for the pooled sample, stock terciles based on average daily volume, and each of the 12 countries. Terciles are constructed using country-specific breakpoints to ensure terciles are similar in the distribution of stocks from each country. $T 1$ (T3) contains stocks with the lowest (highest) average daily traded EUR volume during the sample period. Countries are listed in descending order by their average level of comovement in returns $R_{r}^{2}$. The table reports the mean and standard deviation $(S D)$ of co-movement in returns $\left(R_{r}^{2}\right)$, in price-impact based liquidity $\left(R_{L I Q}^{2}\right)$, in quoted spreads $\left(R_{S P R E A D}^{2}\right)$, in daily volume $\left(R_{D V O L}^{2}\right)$, and in HFT activity $\left(R_{H F T \text { volume }}^{2}\right.$ ). The last four columns report means of market returns (in bps), market liquidity (negative log of Amihud's ILLIQ metric), market volatility (average monthly standard deviation of daily midquote returns in bps), and market-wide average traded volume (in EUR million per stock-day), calculated as equally weighted averages of the respective variable for all stocks in the sample. Standard deviations $(S D)$ are calculated within time, $x_{i t}^{*}=x_{i t}-$ $\bar{x}_{i}$.

\begin{tabular}{lccccccccccccccc}
\hline \multirow{2}{*}{ Sample } & \multirow{2}{*}{$R_{r}^{2}$} & \multicolumn{2}{c}{$R_{L I Q}^{2}$} & \multicolumn{2}{c}{$R_{S P R E A D}^{2}$} & \multicolumn{2}{c}{$R_{D V O L}^{2}$} & \multicolumn{2}{c}{$R_{H F T}^{2}$ volume } & $\begin{array}{c}\text { Market } \\
\text { return }\end{array}$ & $\begin{array}{c}\text { Market } \\
\text { liquidity }\end{array}$ & $\begin{array}{c}\text { Market } \\
\text { volatility }\end{array}$ & $\begin{array}{c}\text { Market } \\
\text { volume }\end{array}$ \\
\hline & Mean & SD & Mean & SD & Mean & SD & Mean & SD & Mean & SD & Mean & Mean & Mean & Mean \\
\hline Pooled & 0.41 & 0.18 & 0.23 & 0.16 & 0.20 & 0.15 & 0.22 & 0.15 & 0.20 & 0.15 & -20.52 & -0.38 & 148.96 & 32.98 \\
\hline Tercile 1 & 0.35 & 0.17 & 0.22 & 0.15 & 0.19 & 0.14 & 0.19 & 0.14 & 0.19 & 0.14 & -20.86 & -0.35 & 150.76 & 32.88 \\
Tercile 2 & 0.41 & 0.18 & 0.23 & 0.15 & 0.21 & 0.16 & 0.21 & 0.15 & 0.19 & 0.14 & -20.34 & -0.39 & 148.08 & 32.98 \\
Tercile 3 & 0.47 & 0.19 & 0.24 & 0.16 & 0.21 & 0.16 & 0.27 & 0.17 & 0.22 & 0.16 & -20.37 & -0.40 & 148.10 & 33.09 \\
\hline Sweden & 0.51 & 0.19 & 0.25 & 0.16 & 0.26 & 0.21 & 0.24 & 0.15 & 0.21 & 0.15 & -25.67 & -0.20 & 190.84 & 21.76 \\
France & 0.51 & 0.19 & 0.21 & 0.14 & 0.21 & 0.18 & 0.27 & 0.17 & 0.23 & 0.16 & -18.97 & -0.04 & 161.78 & 79.53 \\
Germany & 0.47 & 0.19 & 0.23 & 0.15 & 0.17 & 0.13 & 0.28 & 0.18 & 0.20 & 0.16 & -20.94 & -0.05 & 179.06 & 80.92 \\
UK & 0.47 & 0.18 & 0.28 & 0.18 & 0.23 & 0.18 & 0.24 & 0.16 & 0.23 & 0.16 & -19.74 & -0.14 & 160.95 & 35.24 \\
Spain & 0.41 & 0.19 & 0.21 & 0.15 & 0.18 & 0.13 & 0.21 & 0.15 & 0.19 & 0.14 & 21.55 & -0.27 & 127.83 & 43.13 \\
Italy & 0.39 & 0.21 & 0.26 & 0.17 & 0.21 & 0.16 & 0.22 & 0.14 & 0.20 & 0.14 & -21.84 & -0.09 & 175.30 & 45.24 \\
Norway & 0.36 & 0.18 & 0.19 & 0.13 & 0.18 & 0.13 & 0.19 & 0.14 & 0.18 & 0.13 & -24.23 & -1.00 & 162.59 & 10.81 \\
Netherlands & 0.36 & 0.18 & 0.16 & 0.12 & 0.17 & 0.12 & 0.20 & 0.14 & 0.17 & 0.13 & -19.22 & -0.67 & 130.58 & 27.62 \\
Denmark & 0.35 & 0.18 & 0.20 & 0.14 & 0.20 & 0.14 & 0.19 & 0.13 & 0.18 & 0.13 & -25.61 & -0.67 & 119.63 & 5.69 \\
Finland & 0.35 & 0.18 & 0.18 & 0.13 & 0.18 & 0.13 & 0.19 & 0.14 & 0.17 & 0.13 & -18.72 & -0.73 & 116.35 & 13.51 \\
Austria & 0.28 & 0.17 & 0.24 & 0.15 & 0.18 & 0.14 & 0.21 & 0.16 & 0.18 & 0.13 & -20.20 & -0.71 & 125.92 & 3.49 \\
Belgium & 0.24 & 0.16 & 0.17 & 0.12 & 0.17 & 0.12 & 0.18 & 0.13 & 0.16 & 0.12 & -13.10 & -1.09 & 88.29 & 7.99 \\
\hline
\end{tabular}


Table 3

First-stage regressions of the impact of Chi-X on HFT and other variables

This table reports the impact of Chi-X entry on HFT activity and other market characteristics. The estimates are of $\beta$ from the following regression model:

$$
Y_{i, t}=\alpha_{i}+\gamma_{t}+\beta D_{i, t}^{C h i-X}+\varepsilon_{i, t}
$$

where $Y_{i, t}$ is one of the dependent variables shown in the table (two HFT proxies, message traffic, volume, inverse midquote price, volatility, and fragmentation, all defined in Table 1$), D_{i, t}^{C h i-X}$ is a dummy variable equal to one when a stock is traded on Chi-X at that point in time and zero otherwise, and $\alpha_{i}$ and $\gamma_{t}$ are stock and time fixed effects. The regressions are performed on the whole panel and also separately for each tercile of stock by volume. Terciles are constructed using country-specific breakpoints to ensure terciles are similar in the distribution of stocks from each country. $T I$ (T3) contains stocks with the lowest (highest) average daily traded EUR volume during the sample period. Standard errors are robust to heteroskedasticity and within-stock autocorrelation. *, **, *** denote significance at $10 \%, 5 \%, 1 \%$, respectively.

\begin{tabular}{lccccccc}
\hline & $(1)$ & $(2)$ & $(3)$ & $(4)$ & $(5)$ & $(6)$ & $(7)$ \\
Sample & HFTvolume $_{i, t}$ & HFTtrades $_{i, t}$ & messages $_{i, t}$ & dvol $_{i, t}$ & invmidquote $_{i, t}$ & volatility $_{i, t}$ & FRAG2 \\
\hline All & $17.32^{* * *}$ & $4.48^{* *}$ & $31,346.11^{* * *}$ & $-10.88^{* * *}$ & $-0.07^{* * * *}$ & $11.13^{* *}$ & $0.09^{* * *}$ \\
T1 & $11.54^{* * *}$ & $10.68^{* * *}$ & $3,930.69^{* * *}$ & -0.014 & $-0.12^{* * * *}$ & 9.26 & $0.04^{* * *}$ \\
T2 & $8.08^{* * *}$ & -0.51 & $11,330.19^{* * *}$ & $-1.50^{* * *}$ & -0.003 & 2.38 & $0.07 * * *$ \\
T3 & $21.22^{* * *}$ & $4.37^{* * *}$ & $38,839.75^{* * *}$ & $-12.33^{* * *}$ & $0.02 * *$ & 28.57 & $0.10^{* * *}$ \\
\hline
\end{tabular}




\section{Table 4}

Second-stage regressions of the impact of HFT on co-movement

This table reports results from second-stage regressions that analyze the impact of HFT on co-movement in stock returns and in liquidity:

$$
R_{i, \tau}^{2}=\alpha_{i}+\gamma_{\tau}+\beta \widehat{H F T_{l, \tau}}+\sum_{j=1}^{4} \delta_{j} \text { Control }_{j, i, \tau}+\varepsilon_{i, \tau}
$$

$R_{i, \tau}^{2}$ denotes a co-movement measure for stock $i$ in month $\tau$, i.e., co-movement in returns $\left(R_{i, \tau}^{2, r}\right)$ in Panel A and comovement in liquidity $\left(R_{i, \tau}^{2, L I Q}\right)$ in Panel B. $\widehat{H F T_{l, \tau}}$ is the fitted value of HFT activity obtained from the first-stage regression. Control $_{j, i, \tau}$ is a set of four control variables: a fragmentation proxy $\left(F R A G 2_{i, \tau}\right)$, volume $\left(d v o l_{i, \tau}\right)$, volatility ( volatility $_{i, \tau}$ ) and $1 /$ midquote price (invmidquote ${ }_{i, \tau}$ ). $\alpha_{i}$ and $\gamma_{\tau}$ are stock and time fixed effects. The second-stage regressions are estimated for the pooled sample and for each tercile of stocks separately (T1-T3). We construct terciles by volume, liquidity, and volatility, using country-specific breakpoints to ensure terciles are similar in the distribution of stocks from each country. Tl (T3) contains stocks with the lowest (highest) average daily traded EUR volume (or liquidity or volatility) during the sample period. The table reports slope coefficients ( $\beta$ and $\delta_{j}$, with the $\beta$ multiplied by 1,000 ) with $t$-statistics in parentheses. Standard errors are robust to heteroskedasticity and within-stock autocorrelation. *, **, *** denote significance at $10 \%, 5 \%, 1 \%$, respectively. Fstatistic from first-stage regressions test of instrumental relevance are in range from 10.9 to 194.4. The whole panel consists of 32,233 stock-month observations.

\begin{tabular}{|c|c|c|c|c|c|}
\hline \multirow[b]{2}{*}{ Sample } & \multirow[b]{2}{*}{$\widehat{H F T_{l, \tau}}$} & \multicolumn{4}{|c|}{ Control variables } \\
\hline & & $F R A G 2_{i, \tau}$ & $d v o l_{i, \tau}$ & volatility $_{i, \tau}$ & invmidquote $_{i, \tau}$ \\
\hline \multicolumn{6}{|c|}{ Panel A: Impact of HFT on co-movement in returns, $R_{i, \tau}^{2, r}$} \\
\hline Pooled & $\begin{array}{c}\text { 7.197*** } \\
(3.551)\end{array}$ & $\begin{array}{c}-189.035 \\
(-1.345) \\
\end{array}$ & $\begin{array}{c}-0.000 \\
(-0.475)\end{array}$ & $\begin{array}{c}-0.184 * * * \\
(-2.677)\end{array}$ & $\begin{array}{c}-40.692 * \\
(-1.800)\end{array}$ \\
\hline \multicolumn{6}{|c|}{ Volume terciles (T1 - lowest) } \\
\hline $\mathrm{T} 1$ & $\begin{array}{c}18.002 * * * \\
(4.488)\end{array}$ & $\begin{array}{c}-566.584 * \\
(-1.672)\end{array}$ & $\begin{array}{c}-0.000 \\
(-0.133)\end{array}$ & $\begin{array}{c}-0.198 * * \\
(-2.560)\end{array}$ & $\begin{array}{l}35.244 \\
(1.365)\end{array}$ \\
\hline $\mathrm{T} 2$ & $\begin{array}{c}20.146 * * \\
(2.464)\end{array}$ & $\begin{array}{l}-313.126 \\
(-1.138)\end{array}$ & $\begin{array}{c}0.000 \\
(0.396)\end{array}$ & $\begin{array}{l}-0.288 * * \\
(-1.967)\end{array}$ & $\begin{array}{c}-104.750 * * * \\
(-2.689)\end{array}$ \\
\hline $\mathrm{T} 3$ & $\begin{array}{c}-3.550 \\
(-1.307)\end{array}$ & $\begin{array}{c}-104.203 \\
(-0.567)\end{array}$ & $\begin{array}{c}-0.000 * * * \\
(-3.315)\end{array}$ & $\begin{array}{c}-0.139 \\
(-1.596)\end{array}$ & $\begin{array}{c}-154.251 \\
(-1.262)\end{array}$ \\
\hline \multicolumn{6}{|c|}{ Liquidity terciles (T1 - lowest) } \\
\hline $\mathrm{T} 1$ & $\begin{array}{c}15.678 * * * \\
(4.712)\end{array}$ & $\begin{array}{c}-779.854 * * * \\
(-2.626)\end{array}$ & $\begin{array}{c}0.000 * * * \\
(4.506)\end{array}$ & $\begin{array}{c}-0.247 * * * \\
(-3.132)\end{array}$ & $\begin{array}{c}-2.982 \\
(-0.129)\end{array}$ \\
\hline $\mathrm{T} 2$ & $\begin{array}{c}11.204 * * \\
(2.000)\end{array}$ & $\begin{array}{c}-323.925 \\
(-1.069)\end{array}$ & $\begin{array}{c}-0.000 \\
(-1.362)\end{array}$ & $\begin{array}{c}-0.228 * * * \\
(-3.014)\end{array}$ & $\begin{array}{l}-66.747 * \\
(-1.667)\end{array}$ \\
\hline $\mathrm{T} 3$ & $\begin{array}{l}-4.972 * \\
(-1.767)\end{array}$ & $\begin{array}{c}-171.694 \\
(-0.977)\end{array}$ & $\begin{array}{c}-0.000 * * * \\
(-3.904)\end{array}$ & $\begin{array}{c}-0.024 \\
(-0.292)\end{array}$ & $\begin{array}{l}-39.713 \\
(-0.417)\end{array}$ \\
\hline \multicolumn{6}{|c|}{ Volatility terciles (T1 - lowest) } \\
\hline $\mathrm{T} 1$ & $\begin{array}{c}-1.312 \\
(-0.521)\end{array}$ & $\begin{array}{c}371.978 * \\
(1.884)\end{array}$ & $\begin{array}{c}-0.000 * * * \\
(-4.111)\end{array}$ & $\begin{array}{c}2.798 * * * \\
(3.109)\end{array}$ & $\begin{array}{c}689.482 * * \\
(2.301)\end{array}$ \\
\hline $\mathrm{T} 2$ & $\begin{array}{c}11.497 * * * \\
(2.835)\end{array}$ & $\begin{array}{c}-310.111 \\
(-1.145)\end{array}$ & $\begin{array}{c}-0.000 \\
(-0.800)\end{array}$ & $\begin{array}{l}1.252 * * \\
(2.330)\end{array}$ & $\begin{array}{c}-6.844 \\
(-0.100)\end{array}$ \\
\hline $\mathrm{T} 3$ & $\begin{array}{c}12.128 * * * \\
(2.894)\end{array}$ & $\begin{array}{c}-652.045^{* *} \\
(-2.530)\end{array}$ & $\begin{array}{l}0.000 * * \\
(2.070)\end{array}$ & $\begin{array}{c}-0.229 * * * \\
(-3.342)\end{array}$ & $\begin{array}{c}-42.504 * \\
(-1.760)\end{array}$ \\
\hline
\end{tabular}


Table 4 - Continued

\begin{tabular}{|c|c|c|c|c|c|}
\hline \multirow[b]{2}{*}{ Sample } & \multirow[b]{2}{*}{$\widehat{H F T_{l, \tau}}$} & \multicolumn{4}{|c|}{ Control variables } \\
\hline & & $F R A G 2_{i, \tau}$ & $d v o l_{i, \tau}$ & volatility $_{i, \tau}$ & invmidquote $_{i, \tau}$ \\
\hline \multicolumn{6}{|c|}{ Panel B: Impact of HFT on co-movement in liquidity, $R_{i, \tau}^{2, L I Q}$} \\
\hline Pooled & $\begin{array}{c}13.481 * * * \\
(6.327)\end{array}$ & $\begin{array}{c}-290.734 * * \\
(-2.116)\end{array}$ & $\begin{array}{c}0.000 * * * \\
(5.185)\end{array}$ & $\begin{array}{c}-0.071 \\
(-1.352)\end{array}$ & $\begin{array}{l}-20.534 \\
(-1.085)\end{array}$ \\
\hline \multicolumn{6}{|c|}{ Volume terciles (T1 - lowest) } \\
\hline T1 & $\begin{array}{c}29.074 * * * \\
(7.082)\end{array}$ & $\begin{array}{c}-955.147 * * * \\
(-2.851)\end{array}$ & $\begin{array}{c}0.000^{* * *} \\
(4.659)\end{array}$ & $\begin{array}{c}-0.060 * * * \\
(-2.932)\end{array}$ & $\begin{array}{c}63.040^{* * *} \\
(2.236)\end{array}$ \\
\hline $\mathrm{T} 2$ & $\begin{array}{c}29.305 * * * \\
(3.676)\end{array}$ & $\begin{array}{l}-22.765 \\
(-0.089)\end{array}$ & $\begin{array}{c}0.000 * * * \\
(3.219)\end{array}$ & $\begin{array}{c}0.161 \\
(1.376)\end{array}$ & $\begin{array}{c}-139.605 * * * \\
(-4.338)\end{array}$ \\
\hline $\mathrm{T} 3$ & $\begin{array}{c}3.792 \\
(1.364)\end{array}$ & $\begin{array}{c}470.001 * * * \\
(2.754)\end{array}$ & $\begin{array}{c}0.000 \\
(0.845)\end{array}$ & $\begin{array}{c}-0.079 \\
(-0.999)\end{array}$ & $\begin{array}{r}-135.237 \\
(-1.279)\end{array}$ \\
\hline \multicolumn{6}{|c|}{ Liquidity terciles (T1 - lowest) } \\
\hline T1 & $\begin{array}{c}18.793 * * * \\
(5.534)\end{array}$ & $\begin{array}{c}-921.497 * * * \\
(-2.629)\end{array}$ & $\begin{array}{c}0.000 * * * \\
(4.595)\end{array}$ & $\begin{array}{c}-0.022 \\
(-0.832)\end{array}$ & $\begin{array}{c}3.237 \\
(0.132)\end{array}$ \\
\hline $\mathrm{T} 2$ & $\begin{array}{c}30.746 * * * \\
(5.036)\end{array}$ & $\begin{array}{c}-733.249 * * \\
(-2.250)\end{array}$ & $\begin{array}{c}-0.000 * * * \\
(-3.344)\end{array}$ & $\begin{array}{c}0.037 \\
(0.400)\end{array}$ & $\begin{array}{c}-79.255^{* * * *} \\
(-3.342)\end{array}$ \\
\hline $\mathrm{T} 3$ & $\begin{array}{c}2.756 \\
(0.970) \\
\end{array}$ & $\begin{array}{c}422.866^{* * *} \\
(2.518) \\
\end{array}$ & $\begin{array}{c}0.000 \\
(0.545) \\
\end{array}$ & $\begin{array}{c}-0.013 \\
(-0.139) \\
\end{array}$ & $\begin{array}{l}-40.502 \\
(-0.460) \\
\end{array}$ \\
\hline \multicolumn{6}{|c|}{ Volatility terciles $(\mathrm{T} 1-$ lowest $)$} \\
\hline T1 & $\begin{array}{c}14.672 * * * \\
(5.014)\end{array}$ & $\begin{array}{l}-32.699 \\
(-0.155)\end{array}$ & $\begin{array}{c}0.000 * * * \\
(4.963)\end{array}$ & $\begin{array}{c}1.154 \\
(1.326)\end{array}$ & $\begin{array}{c}-517.857 * \\
(-1.699)\end{array}$ \\
\hline $\mathrm{T} 2$ & $\begin{array}{c}10.952 * * * \\
(2.609)\end{array}$ & $\begin{array}{l}-46.917 \\
(-0.172)\end{array}$ & $\begin{array}{c}0.000 \\
(1.414)\end{array}$ & $\begin{array}{c}0.769 \\
(1.526)\end{array}$ & $\begin{array}{l}49.798 \\
(0.805)\end{array}$ \\
\hline $\mathrm{T} 3$ & $\begin{array}{c}13.965^{* * * *} \\
(3.318)\end{array}$ & $\begin{array}{c}-780.954 * * * \\
(-3.335)\end{array}$ & $\begin{array}{c}0.000 * * \\
(2.546) \\
\end{array}$ & $\begin{array}{c}-0.079 \\
(-1.505) \\
\end{array}$ & $\begin{array}{l}-28.066 \\
(-1.409) \\
\end{array}$ \\
\hline
\end{tabular}




\section{Table 5}

Second-stage regressions of the impact of HFT on other stock characteristics

This table reports results from second-stage regressions that analyze the impact of HFT on various stock characteristics:

$$
Y_{i, \tau}=\alpha_{i}+\gamma_{\tau}+\beta \widehat{H F T_{l, \tau}}+\sum_{j=1}^{4} \delta_{j} \text { Control }_{j, i, \tau}+\varepsilon_{i, \tau}
$$

$Y_{i, \tau}$ is one of the following dependent variables for stock $i$ in month $\tau$ : average daily midquote return $\left(r_{i, \tau}\right)$, average liquidity $\left(L I Q_{i, \tau}\right)$, average relative quoted spread $\left(\operatorname{spread}_{i, \tau}\right)$, and average volatility (standard deviation) of daily midquote returns ( volatility $_{i, \tau}$ ). $\widehat{H F T_{l, \tau}}$ is the fitted value of HFT activity obtained from the first-stage regressions. Control $_{j, i, \tau}$ is a set of four control variables: a fragmentation proxy $\left(F R A G 2_{i, \tau}\right)$, volume $\left(d v o l_{i, \tau}\right)$, volatility $\left(\right.$ volatility $_{i, \tau}$ ) and $1 /$ midquote (invmidquote $\left.e_{i, \tau}\right) . \alpha_{i}$ and $\gamma_{\tau}$ are stock and time fixed effects. The table reports slope coefficients $\left(\beta\right.$ and $\left.\delta_{j}\right)$ with $t$-statistics in parentheses. Standard errors are robust to heteroskedasticity and withinstock autocorrelation. $*, * *, * * *$ denote significance at $10 \%, 5 \%, 1 \%$, respectively.

\begin{tabular}{lccccc}
\hline Dependent & & \multicolumn{4}{c}{ Control variables } \\
\cline { 3 - 6 } variable & ${\widehat{H F T_{l, \tau}}}_{n}$ & $F R A G 2_{i, \tau}$ & $d v o l_{i, \tau}$ & volatility $_{i, \tau}$ & invmidquote $_{i, \tau}$ \\
\hline$r_{i, \tau}$ & -0.217 & $18.966^{* *}$ & 0.000 & -0.003 & -0.692 \\
LIQ $_{i, \tau}$ & $(-1.532)$ & $(2.067)$ & $(0.206)$ & $(-0.107)$ & $(-0.255)$ \\
& $0.019^{* * *}$ & $0.581^{* * *}$ & $0.000^{* * *}$ & $-0.000^{* * *}$ & 0.024 \\
spread $_{i, \tau}$ & $(15.024)$ & $(7.310)$ & $(13.401)$ & $(-3.547)$ & $(0.694)$ \\
& $-3.534^{* * *}$ & $-90.116^{* * *}$ & $0.000^{* * *}$ & $0.086^{* *}$ & $45.170^{* * *}$ \\
volatility $_{i, \tau}$ & $(-11.903)$ & $(-5.000)$ & $(-10.417)$ & $(2.198)$ & $(4.934)$ \\
& $2.841^{* *}$ & $-67.814 *$ & $0.000^{* *}$ & & $23.659^{* * *}$ \\
& $(2.325)$ & $(-1.870)$ & $(2.149)$ & & $(4.067)$ \\
\hline
\end{tabular}




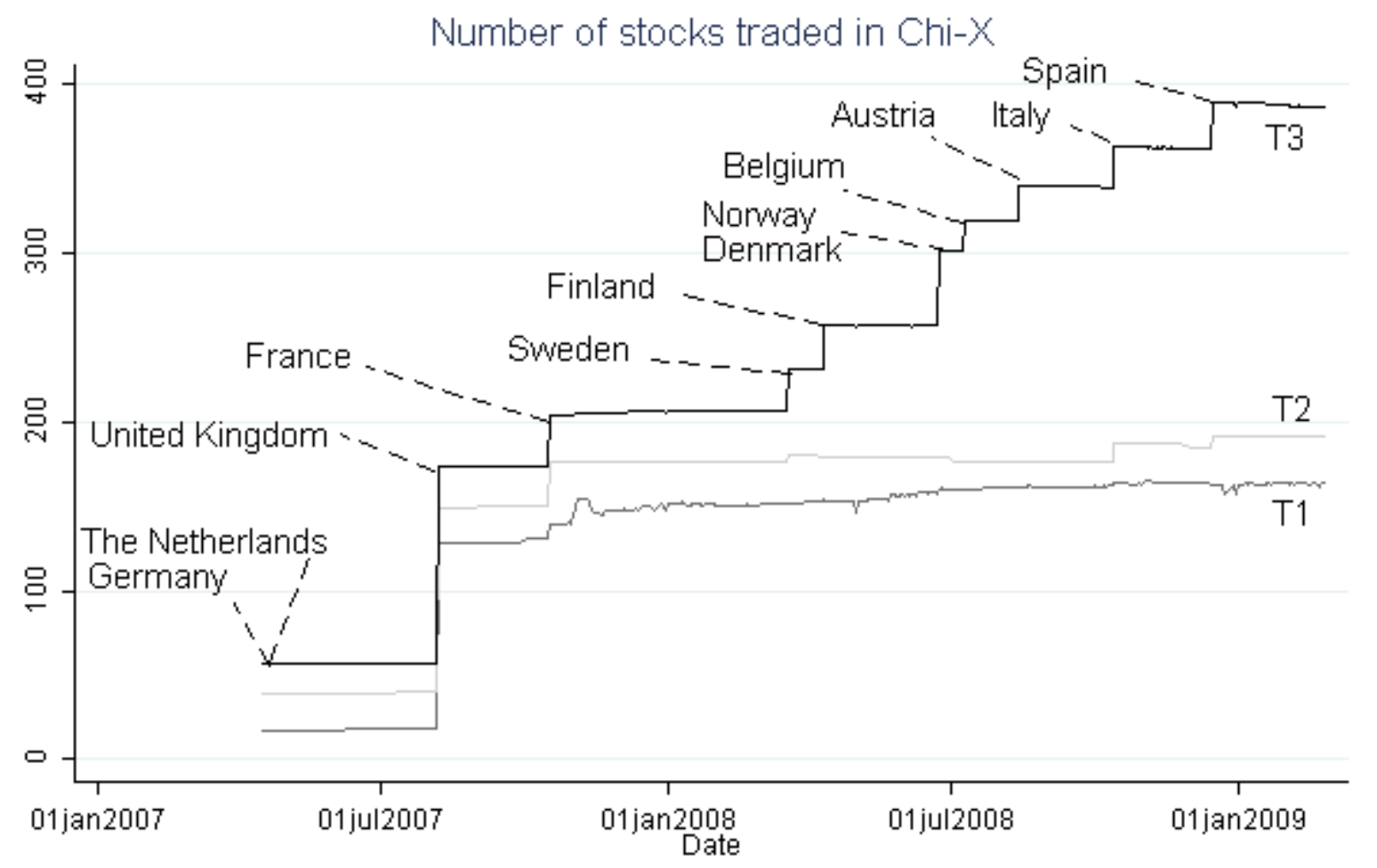

Fig. 1. Number of stocks traded on Chi-X through time. The graph illustrates the staggered introduction of Chi-X to European equity markets. The vertical axis measures the number of stocks in each traded volume tercile of our sample traded on Chi-X on each day during the sample period. Terciles are constructed using country-specific breakpoints to ensure terciles are similar in the distribution of stocks from each country. $T 1$ (T3) contains stocks with the lowest (highest) average daily traded EUR volume during the sample period. 


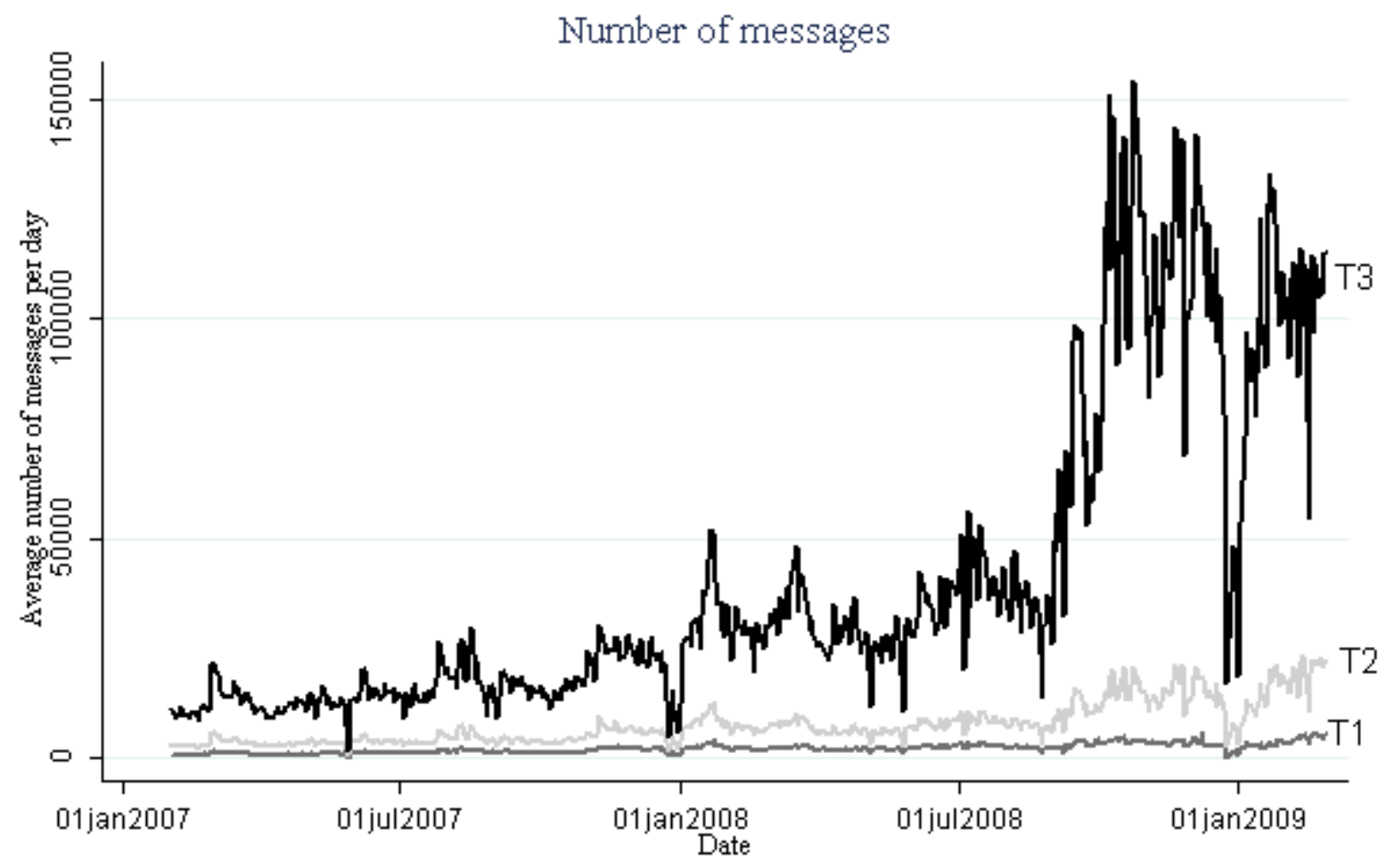

Fig. 2. Daily number of quote messages. The graph shows the average number of quote messages (number of changes to the price or volume at the best quotes, measured each stock-day) through time for terciles of traded EUR volume. Terciles are constructed using country-specific breakpoints to ensure terciles are similar in the distribution of stocks from each country. $T 1$ (T3) contains stocks with the lowest (highest) average daily traded EUR volume during the sample period. 


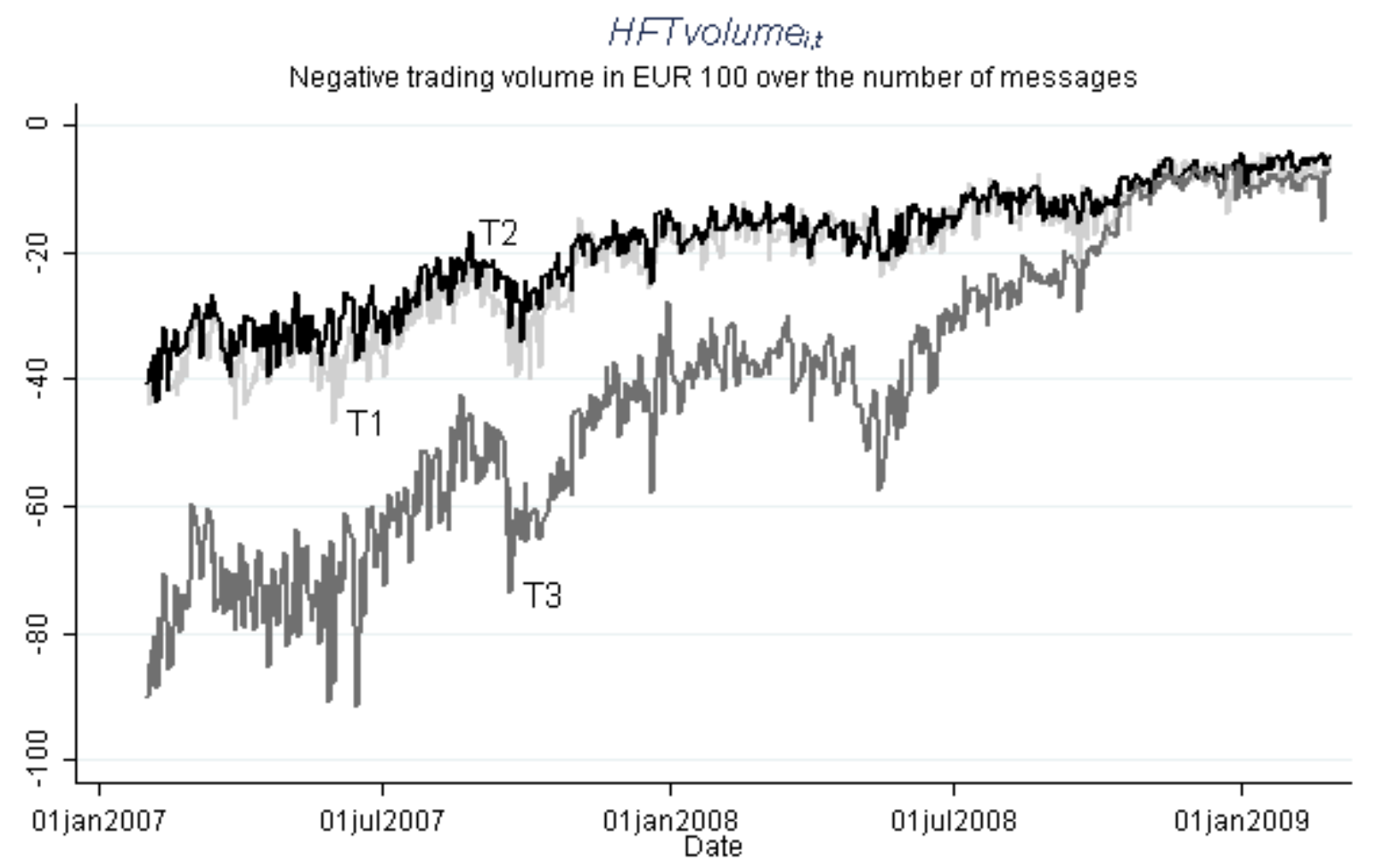

Fig. 3. HFT activity through time. The graph shows HFT activity (ratio of negative trading volume (in '00 EUR) to the number of quote messages) through time for terciles of traded EUR volume. Terciles are constructed using country-specific breakpoints to ensure terciles are similar in the distribution of stocks from each country. Tl (T3) contains stocks with the lowest (highest) average daily traded EUR volume during the sample period. 

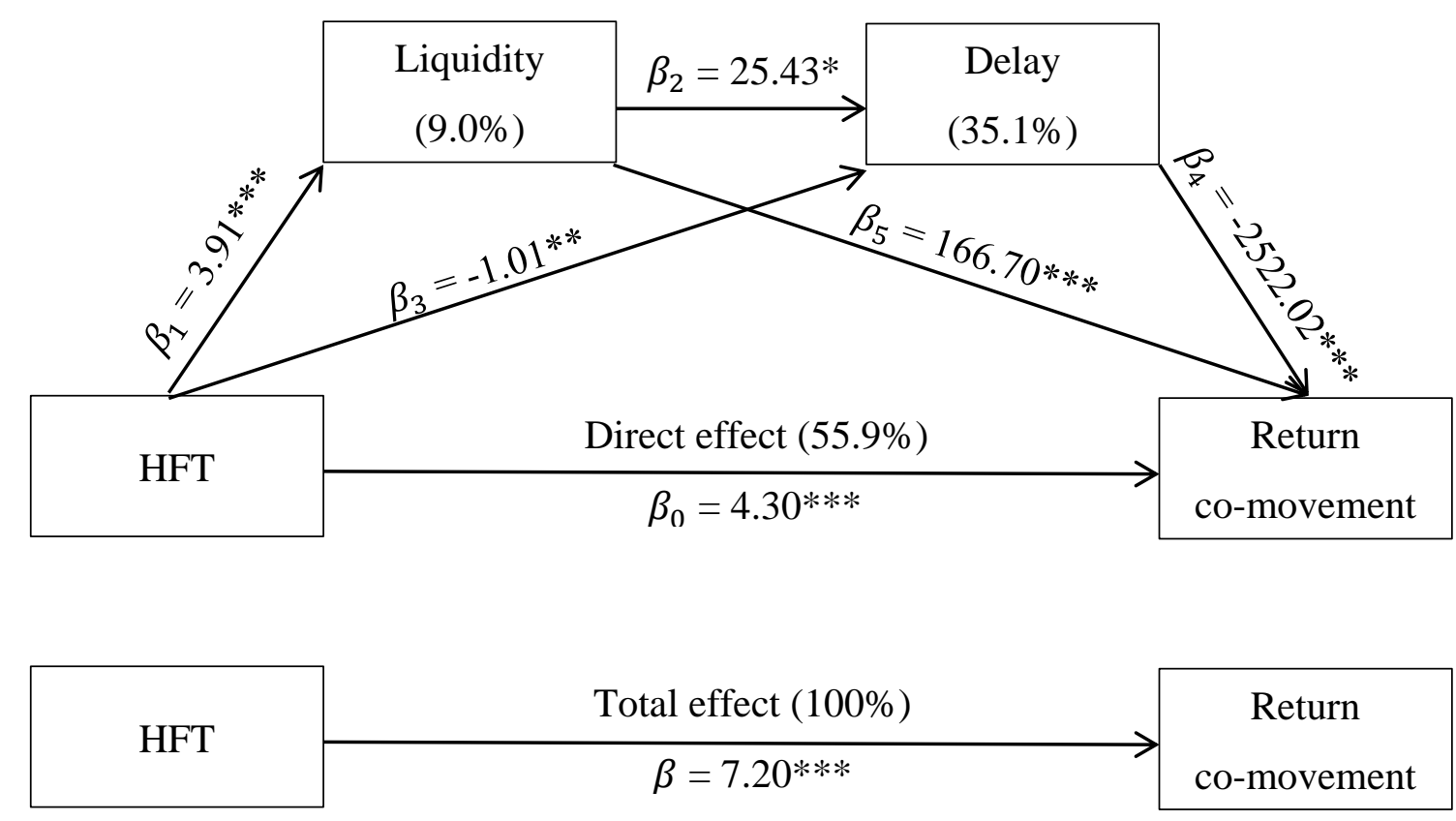

Fig. 4. Direct and mediated effects of HFT on co-movement in returns. This graph depicts the results from multiple mediation analysis of the channels by which HFT impacts return co-movement. The estimates are derived from the following set of panel regressions using stock-month $(i, \tau)$ observations:

$$
\begin{gathered}
R_{i, \tau}^{2, r}=\alpha_{i}+\gamma_{\tau}+\beta \widehat{H F T_{l, \tau}}+\sum_{j=1}^{4} \delta_{j} \text { Control }_{j, i, \tau}+\varepsilon_{i, \tau} \\
L_{i, \tau}=\alpha_{i}+\gamma_{\tau}+\beta_{1} \widehat{H F T_{l, \tau}}+\sum_{j=1}^{4} \delta_{j} \text { Control }_{j, i, \tau}+\varepsilon_{i, \tau} \\
\operatorname{delay}_{i, \tau}=\alpha_{i}+\gamma_{\tau}+\beta_{3}{\widehat{H F T_{l, \tau}}}_{3} \beta_{2} L_{i, \tau}+\sum_{j=1}^{4} \delta_{j} \text { Control }_{j, i, \tau}+\varepsilon_{i, \tau} \\
R_{i, \tau}^{2, r}=\alpha_{i}+\gamma_{\tau}+\beta_{0} \overline{H F T}_{l, \tau}+\beta_{5} \text { LIQ }_{i, \tau}+\beta_{4} \text { delay }_{i, \tau}+\sum_{j=1}^{4} \delta_{j} \text { Control }_{j, i, \tau}+\varepsilon_{i, \tau}
\end{gathered}
$$

where $R_{i, \tau}^{2, r}$ is co-movement in returns, $L I Q_{i, \tau}$ is liquidity, $\widehat{H F T_{l, \tau}}$ is the fitted value of HFT activity from the firststage regressions that use Chi-X as an instrumental variable, delay $_{i, \tau}$ is a measure of the delay with which the stock's price reflects market-wide information, Control $_{j, i, \tau}$ is a set of four control variables: a fragmentation proxy $\left(F R A G 2_{i, \tau}\right)$, volume $\left(d v o l_{i, \tau}\right)$, volatility (volatility $\left.y_{i, \tau}\right)$ and the inverse of the midquote price (invmidquote $\left.e_{i, \tau}\right) . \alpha_{i}$ and $\gamma_{\tau}$ are stock and time fixed effects. The percentages refer to the strength of the channel as a proportion of the total effect. $*, * *, * * *$ denote significance at $10 \%, 5 \%, 1 \%$, respectively. 

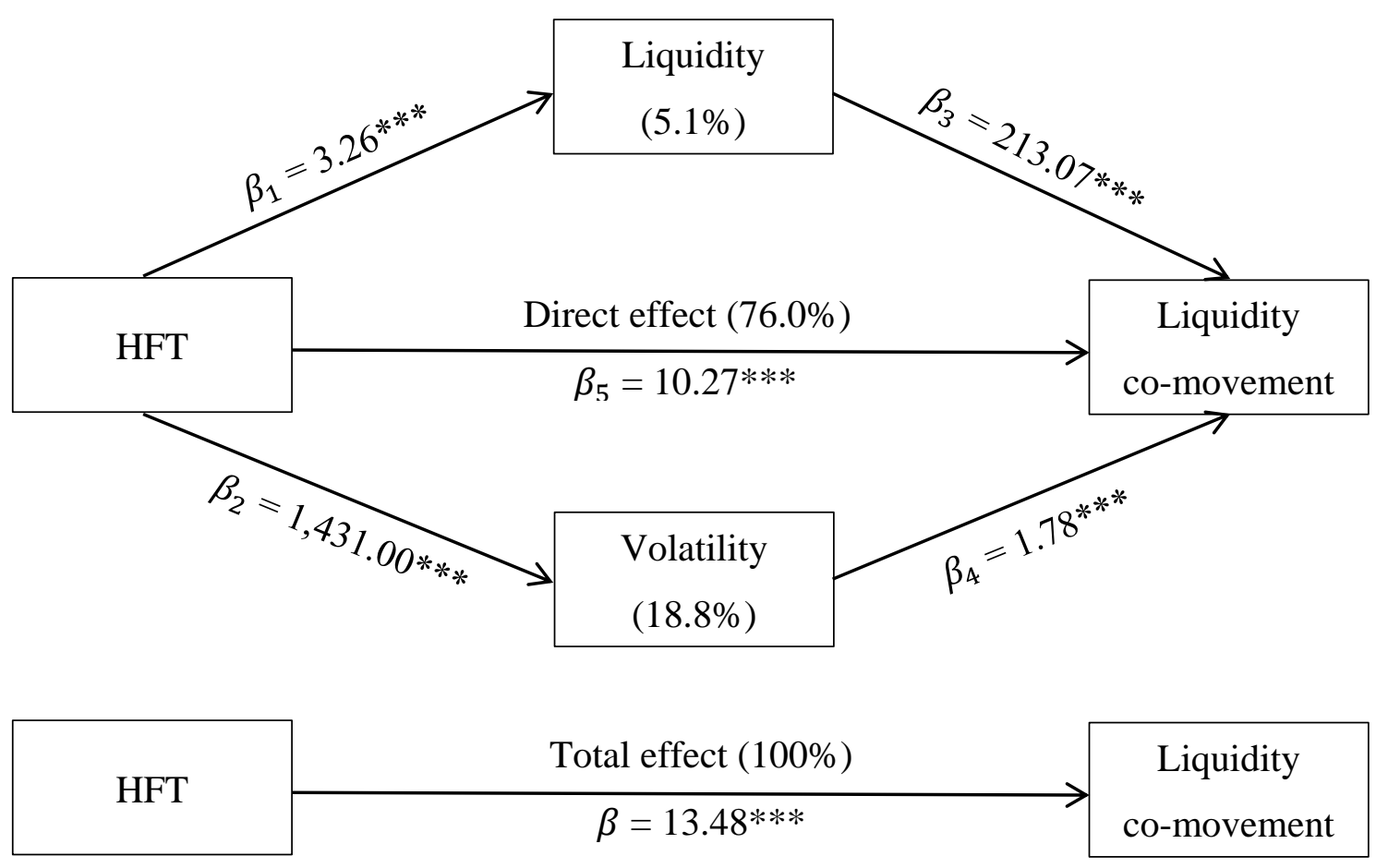

Fig. 5. Direct and mediated effects of HFT on co-movement in liquidity. This graph depicts the results from multiple mediation analysis of the channels by which HFT impacts liquidity co-movement. The estimates are derived from the following set of panel regressions using stock-month $(i, \tau)$ observations:

$$
\begin{aligned}
& R_{i, \tau}^{2, L I Q}=\alpha_{i}+\gamma_{\tau}+\beta \widehat{H F T}_{l, \tau}+\sum_{j=1}^{4} \delta_{j} \text { Control }_{j, i, \tau}+\varepsilon_{i, \tau} \\
& L I Q_{i, \tau}=\alpha_{i}+\gamma_{\tau}+\beta_{1} \widehat{H F T}_{l, \tau}+\sum_{j=1}^{4} \delta_{j} \operatorname{Control}_{j, i, \tau}+\varepsilon_{i, \tau} \\
& \text { volatility }_{i, \tau}=\alpha_{i}+\gamma_{\tau}+\beta_{2} \widehat{H F T}_{l, \tau}+\sum_{j=1}^{4} \delta_{j} \text { Control }_{j, i, \tau}+\varepsilon_{i, \tau} \\
& R_{i, \tau}^{2, L I Q}=\alpha_{i}+\gamma_{\tau}+\beta_{5} \widehat{H F T}_{l, \tau}+\beta_{3} L_{I} Q_{i, \tau}+\beta_{4} \text { volatility }_{i, \tau}+\sum_{j=1}^{3} \delta_{j} \text { Control }_{j, i, \tau}+\varepsilon_{i, \tau}
\end{aligned}
$$

where $R_{i, \tau}^{2, L I Q}$ is co-movement in liquidity, $L I Q_{i, \tau}$ is liquidity, volatility $y_{i, \tau}$ is volatility, $\widehat{H F T_{l, \tau}}$ is the fitted value of HFT activity from the first-stage regressions that use Chi-X as an instrumental variable, Control $_{j, i, \tau}$ is a set of four control variables: a fragmentation proxy $\left(F R A G 2_{i, \tau}\right)$, volume $\left(d v o l_{i, \tau}\right)$, volatility $\left(\right.$ volatility $\left._{i, \tau}\right)$ and the inverse of the midquote price (invmidquote $e_{i, \tau}$ ). $\alpha_{i}$ and $\gamma_{\tau}$ are stock and time fixed effects. The percentages refer to the strength of the channel as a proportion of the total effect. *,**,*** denote significance at $10 \%, 5 \%, 1 \%$, respectively. 